\title{
Time in Eating and Food Preparation among Single Adults
}

\author{
Mark C. Senia, Helen H. Jensen, and Oleksandr Zhylyevskyy
}

Working Paper 14-WP 549

June 2014

\author{
Center for Agricultural and Rural Development \\ lowa State University \\ Ames, lowa 50011-1070 \\ www.card.iastate.edu
}

Mark C. Senia, Department of Agricultural Economics, Texas A\&M University, Agriculture and Life Sciences Bldg., 2124 TAMU, College Station TX 77843. E-mail: mcsenia@tamu.edu.

Helen H. Jensen, Iowa State University, 578 Heady Hall, Ames, IA 50011.

E-mail: hhjensen@iastate.edu

Oleksandr Zhylyevskyy, Department of Economics, lowa State University, 460D Heady Hall, Ames, IA 50011. E-mail: oz9a@iastate.edu.

This publication is available online on the CARD website: www.card.iastate.edu. Permission is granted to reproduce this information with appropriate attribution to the author and the Center for Agricultural and Rural Development, lowa State University, Ames, lowa 50011-1070.

Funding for this research was provided in part by the U.S. Department of Agriculture award \#2012-70002-19386 to the Center for Agricultural and Rural Development at lowa State University.

For questions or comments about the contents of this paper, please contact Helen $\mathrm{H}$. Jensen, hhjensen@iastate.edu.

Iowa State University does not discriminate on the basis of race, color, age, ethnicity, religion, national origin, pregnancy, sexual orientation, gender identity, genetic information, sex, marital status, disability, or status as a U.S. veteran. Inquiries can be directed to the Interim Assistant Director of Equal Opportunity and Compliance, 3280 Beardshear Hall, (515) 294-7612. 


\title{
Time in Eating and Food Preparation among Single Adults
}

\author{
Mark C. Senia, ${ }^{a}$ Helen H. Jensen, ${ }^{b}$ Oleksandr Zhylyevskyyc \\ aDepartment of Agricultural Economics, Texas A\&M University, Agriculture and Life Sciences Bldg., 2124 TAMU, \\ College Station, TX 77843, USA. E-mail: mcsenia@tamu.edu \\ ${ }^{\mathrm{b} C o r r e s p o n d i n g ~ a u t h o r . ~ D e p a r t m e n t ~ o f ~ E c o n o m i c s, ~ I o w a ~ S t a t e ~ U n i v e r s i t y, ~} 578$ Heady Hall, Ames, IA 50011, USA. \\ Phone: 1-515-294-6253. Fax: 1-515-294-6336. E-mail: hhjensen@iastate.edu \\ 'Department of Economics, Iowa State University, 460D Heady Hall, Ames, IA 50011, USA. E-mail: oz9a@iastate.edu
}

June 2014

\begin{abstract}
We investigate factors affecting the duration of eating and food preparation among adults in single decision-maker households. Eating time is differentiated into primary and secondary eating time and further differentiated by location: at home vs. away from home. We construct a simple theoretical model, based on Becker's household production approach, to motivate empirical equations for eating and food preparation time. Empirical analysis is performed using data from the 2006-2008 Eating and Health (EH) Module of the American Time Use Survey (ATUS). Higher food-at-home prices are found to be associated with more time in food preparation and primary eating at home. Higher fast food prices are associated with more time in food preparation and less time in primary eating at home. We conclude that food prices influence home production and time allocation decisions. We also find that low-income adults spend more time in food preparation and primary eating at home and are less likely to eat away from home than those with more income. The presence of children in the household is associated with more time in food preparation and less time in primary eating away from home. Public policies attempting to effect an increase in food preparation among low-income, single adult households with children may need to account for limited opportunities such households can have to acquire and prepare healthier foods when additional time is required.
\end{abstract}

Keywords: eating time, food preparation time, American Time Use Survey

JEL Classification: D12, D13, Q18 


\section{Time in Eating and Food Preparation among Single Adults}

\section{Introduction}

Access to economic resources and opportunities varies significantly across individuals. In contrast, everyone is equally endowed with 24 hours per day. The decision on how to allocate this limited time can profoundly affect one's health and well-being. Following a line of the economics literature investigating time devoted to a variety of health-related activities (e.g., Biddle and Hamermesh 1990), we study factors affecting the duration of eating and the duration of food preparation, an activity closely related to eating, in the United States. ${ }^{1}$ Gaining a better understanding of these factors is critical in view of substantial changes over the last several decades in the patterns of eating and food preparation time in the United States and elsewhere. Such changes include increased snacking (Popkin and Duffey 2010), a shift in the composition of eating time away from primary eating and toward secondary eating, ${ }^{2}$ and a decline in food preparation time (especially among women, see Zick and Stevens 2010; Möser 2010). This shift in time use is often attributed to concurrent changes in the economic, technological, and food environment (Cutler et al. 2003) and can have important implications for individual health outcomes and public policy (Ma et al. 2003; Howarth et al. 2007; Hamermesh 2010; Kolodinsky and Goldstein 2011). The significant changes in eating patterns and the potential health effects underscore the need to better understand eating time and factors that can explain differences.

In this paper, we focus on the time allocation decisions of adults from single decision-maker householdsdefined here as households containing a single childless adult (aged eighteen years or more) or a single adult and related children under the age of sixteen. We extend previous studies on eating time (e.g., Hamermesh 2007; 2010) to perform a more detailed analysis by differentiating between primary eating time vs. secondary eating time and by further distinguishing between primary and secondary eating time at home vs. away from home. As explained in Section 3, eating is said to occur "at home” if it takes place in one's own home or yard, and “away from home” if it takes place elsewhere (at work, at a restaurant, in the car, and so on). A novelty of our work is the inclusion of food prices in the analysis to account for their possible impact on the duration of eating and food preparation. Another novelty is that we investigate the different types of eating time along with food preparation time.

This paper has two main objectives. The first objective is to identify and better understand the effects of food prices on eating and food preparation time. Significant changes have occurred in household and market technologies that influence decisions about time in eating activities and food preparation and about eating location. In fact, many individuals today choose increasingly to rely more on eating away from home than on eating at home (Cutler et al. 2003). We construct an index of food-at-home prices and an index of fast food prices and use them to examine the choices over eating and food preparation time. This focus is especially important in the development of

\footnotetext{
${ }^{1}$ For brevity, we often use the term "eating” to mean "eating and drinking."

${ }^{2}$ Roughly speaking, a "primary” activity is an individual's main activity and "secondary” activity is an activity occurring concurrently with a primary activity. Section 3.2 provides details in the context of eating time.
} 
public policies that affect food prices and food acquisition for low-income households. Our second objective is to ascertain the role of other factors, especially socioeconomic variables, in eating and food preparation time.

By distinguishing among the different types of eating time and associated effects of food prices and other factors, we improve on the existing literature through more accurate accounting for the increasingly complex nature of eating activities. In particular, many individuals today attempt to "economize" on eating time via multitasking. For example, they eat while watching television or while working — or more generally, they engage in eating as a secondary, rather than primary, activity (Cutler et al. 2003; Bertrand and Schanzenbach 2009; Hamermesh 2010; Zick and Stevens 2010). Analyzing secondary eating time separately from primary eating time is important due to their potentially different impacts on health. For instance, individuals may be relatively less able to control their food and caloric intake (i.e., pay attention to what and how much they eat) during secondary eating time, because they are distracted by some other, concurrent activity (Bellisle and Dalix 2001; Poothullil 2002). Also, investigating eating time away from home separately from eating time at home is important because foods consumed away from home can be of lower nutritional quality in comparison to foods consumed at home (Lin and Guthrie 2012), which has implications for health.

We gain additional insight by analyzing eating time along with food preparation time. To save on food preparation time, individuals can utilize a number of strategies aimed at substituting monetary expenditures for the input of time. For example, they may choose to purchase more of processed food items (e.g., "convenience” foods), which require relatively less time to handle when preparing meals (for details on the strategies aimed at substituting between time and monetary expenditures when preparing meals, see Leibtag and Kaufman 2003; Aguiar and Hurst 2007). Changes in the nutritional content of the foods consumed resulting from the food preparation decisions can affect health.

To address our research objectives, we develop an empirical framework for studying time use that accounts for the individual's decision to allocate his or her time across a range of food-related activities. This framework draws on a relatively simple theoretical model based on Becker’s (1965) household production approach. Empirically, we investigate the duration of the following five activities: (1) primary eating at home, (2) primary eating away from home, (3) secondary eating at home, (4) secondary eating away from home, and (5) food preparation. Since individual activity durations are zero for a non-trivial fraction of sample observations, we utilize econometric techniques aimed to account for this data feature. Namely, we implement and compare a Tobit (Tobin 1958) and double-hurdle model (Cragg 1971) approaches. Our main conclusions are based on estimates from the double-hurdle modeling approach, which is more flexible.

We perform the empirical analysis using data from the Eating and Health (EH) Module of the American Time Use Survey (ATUS) pooled across the years 2006, 2007, and 2008 (these three years are the only years when the EH Module was administered). This nationally representative dataset is well suited for the analysis because it 
provides us with information on food preparation time and eating time, including secondary eating time, and allows us to distinguish between eating time at home and away from home. We restrict the analysis to a sample of adults from single decision-maker households. The time in eating and food preparation among adults from single decisionmaker households holds a significant research interest. These households are often believed to be relatively more time-constrained than others. In particular, they can be "time-poor" (Vickery 1977), that is, have a subpar standard of living due to insufficient time available for subsistence levels of home production (see Douthitt 2000, p. 9). Kalenkoski and Hamrick (2013) show that adults in "time-poor" households can differ from others in terms of their eating pattern, including the location of eating. Also, differences in the relative severity of time constraints can have implications for differences in time spent in eating and food preparation (Zick et al. 1996), as well as consequences for dietary intake and the monetary expenditures required to attain an adequate diet (Davis and You 2011).

Our main empirical results are as follows. We find that food prices can explain some of the differences in the pattern of time use. For example, higher food-at-home prices are associated with more time in food preparation and primary eating at home. In turn, higher fast food prices are linked to more time in food preparation and less time in primary eating at home. We also find that as income increases, individuals devote less time to eating at home and more time to eating away from home. In comparison, those at or near poverty devote more time to food preparation and eating at home and less time to eating away from home. The presence of children in the household is associated with less time in primary eating away from home; and it also tends to increase food preparation time. Although most single adults do their primary eating at home, the fact that a substantial fraction of them engage in secondary eating and eating away from home may have significant consequences for dietary quality and health if the types of foods consumed in these ways differ from those consumed during primary eating at home.

The remainder of the paper is organized as follows. Section 2 constructs a simple theoretical model of time use to motive the empirical analysis. Section 3 describes the data. Section 4 outlines the econometric approach. Section 5 presents the estimation results. Section 6 concludes.

\section{Theoretical Framework}

To motivate the empirical specification (see Section 4), we construct a simple theoretical model of time use that draws on the standard household production framework (Becker 1965; Pollak and Wachter 1975; Gronau 1977). Our model is similar to that discussed by Davis (2013). In this paper, we choose to focus on the case of single decision-maker households. More specifically, we analyze decisions of households that include exactly one adult (aged eighteen years or more) and may also include children under the age of sixteen years. Thus, we investigate only decisions of single childless adults and of single adults with related children younger than sixteen present in the household. ${ }^{3}$ We do not study households with older children present because, as Dauphin et al. (2011) show,

\footnotetext{
${ }^{3}$ Households with children aged sixteen years or more are excluded from consideration. The empirical specification controls for the presence of younger children in the household, differentiated by the child's age.
} 
children aged sixteen years or more are likely to be decision-makers in the household. A different analytical approach than the one pursued here—for example, the collective model (e.g., Chiappori 1997)—would be needed to investigate decisions of households with two or more decision-makers, including married-couple households and households containing children aged sixteen years or more. In fact, empirical estimates of You and Davis (2010) for a model involving food preparation time suggest that our analytical approach would not be appropriate to study time allocation choices of two-parent households.

The decision-maker's preferences are defined over food commodities (i.e., meals and snacks as eaten), a composite commodity of all non-food goods, and leisure, and are represented by a utility function

$$
U=U(F H, F A, Z, L ; \tau),
$$

where $F H$ is the quantity of a food commodity related to eating at home, $F A$ is the quantity of a food commodity related to eating away from home, $Z$ is the quantity of the composite commodity (all non-food goods), $L$ is the amount of leisure time, and $\tau$ is a vector of individual and household characteristics affecting utility. Some of the elements of $\tau$ are observed by the researcher (e.g., age, gender, and race of the decision-maker), but others are unobservable (e.g., individual time-use preferences). By specifying that the two food commodities enter the utility function separately, we implicitly allow them to be imperfect substitutes.

The food commodities, $F H$ and $F A$, are produced according to two different production functions. First,

$$
F H=F\left(X H, P H, S H, R ; \mu_{1}\right),
$$

where $\mathrm{XH}$ represents market good inputs (e.g., groceries), $\mathrm{PH}$ is the amount of time in primary eating at home, $\mathrm{SH}$ is the amount of time in secondary eating at home, $R$ is the amount of time in food preparation, and $\mu_{1}$ is a vector of individual and household characteristics affecting production efficiency (e.g., the educational attainment of the decision-maker), some of which may be unobservable by the researcher. Second,

$$
F A=G\left(X A, P A, S A ; \mu_{2}\right),
$$

where $X A$ represents market good inputs (e.g., meals purchased at a restaurant), $P A$ is the amount of time in primary eating away from home, $S A$ is the amount of time in secondary eating away from home, and $\mu_{2}$ is a vector of characteristics affecting production efficiency (again, some of these characteristics may be unobservable by the researcher). ${ }^{4}$ The vectors $\mu_{1}$ and $\mu_{2}$ need not comprise the same set of characteristics in general but may overlap. Notice that we distinguish between primary and secondary eating time inputs: $P H$ and $S H$, respectively, in the case of the production function $F(\cdot)$ in Eq. (2); and $P A$ and $S A$, respectively, in the case of the production function $G(\cdot)$ in Eq. (3). This setup allows for the primary and secondary eating time inputs to have different marginal product schedules if secondary eating time is relatively less "productive,” for example. The setup also allows for

\footnotetext{
${ }^{4}$ Unlike Eq. (2), Eq. (3) does not contain a food preparation time variable. First, many activities underlying eating away from home do not involve food preparation (e.g., eating at a restaurant). Second, the data do not allow us to distinguish food preparation related to eating at home from that related to eating away from home (e.g., preparing snacks at home for consumption in the workplace). Thus, we choose to include $R$ only in Eq. (2).
} 
substitutability between market goods and food preparation time and for complementarity between market goods and eating time in the food commodity production.

The decision-maker faces two time constraints. First, the total available time must be split between work, leisure, primary eating at home and away from home, and food preparation:

$$
H+L+P H+P A+R=T,
$$

where $H$ is the amount of work time and $T$ is the time endowment (e.g., 24 hours per day). To clarify, $H$ refers to market work (i.e., work performed for pay—see the budget constraint below). The time spent in (unpaid) home production activities other than food preparation (e.g., cleaning one's own home or doing laundry) is implicitly included in $L$. Because the empirical analysis only investigates food-related time use, we do not include those other home production activities separately in the model. In addition, it should be noted that our empirical definition of food preparation time, $R$, encompasses time in food and drink preparation (e.g., actual cooking) as well as time in grocery shopping and directly related travel. In comparison, primary eating time at home, $P H$, and away from home, $P A$, only incorporate time in actual eating, rather than also time in travel. Thus, the time spent traveling to a restaurant in order to eat away from home-an example of eating-related travel time-is implicitly included either in $L$ if eating was not part of the job, or in $H$ if it was part of the job. Our empirical definitions of eating time and food preparation time closely follow the existing literature on time use; see Section 3 for details.

Second, while the time in secondary eating does not affect Eq. (4) because secondary eating occurs concurrently with work, leisure, or food preparation (i.e., concurrently with activities other than primary eating), an additional time constraint must be specified to account for the fact that the time in secondary eating cannot, in principle, exceed the time in these three (primary) activities:

$$
S H+S A \leq H+L+R .
$$

The data collection procedure of the EH Module and our approach to constructing secondary eating time variables (see Section 3) are such that the inequality in Eq. (5) is automatically enforced. In fact, this inequality does not play any notable role in the empirical analysis. However, it is needed here to provide a complete description of the time constraints faced by the decision-maker in the theoretical model. In addition, it helps to illustrate the conceptual difference between primary and secondary eating time in the model. ${ }^{5}$

In addition, there is a budget constraint:

$$
P_{X H} \cdot X H+P_{X A} \cdot X A+Z=W \cdot H+V,
$$

where $P_{X H}$ is the price of $X H$ (e.g., price of groceries), $P_{X A}$ is the price of $X A$ (e.g., price of restaurant meals), $W$ is the wage rate, $V$ is non-labor income, and the price of $Z$ is normalized to one.

\footnotetext{
${ }^{5}$ Strictly speaking, the inequality in Eq. (5) should be specified as two inequalities, differentiated with respect to the location of work, leisure, and food preparation. In that case, the time in secondary eating at home cannot exceed the time in work, leisure, and food preparation occurring at home, whereas the time in secondary eating away from home cannot exceed the time in work, etc. occurring away from home. This complication adds little insight from the standpoint of our empirical analysis and is not pursued here.
} 
The decision-maker chooses how much of each market good to buy and how to allocate time across the various activities by maximizing the utility function in Eq. (1) subject to technological constraints embedded in the production functions in Eqs. (2) and (3), the time constraints in Eqs. (4) and (5), the budget constraint in Eq. (6), and non-negativity constraints (the latter constraints arise because the quantity of a market good purchased and the amount of time devoted to an activity must be non-negative). Given a suitable set of regularity conditions, this constrained maximization problem will have a solution, which will specify, among its elements, the optimal time in each of the four types of eating and in food preparation:

$$
\begin{aligned}
& P H^{*}=P H\left(P_{X A}, P_{X H}, W, V, \tau, \mu_{1}, \mu_{2}\right), \\
& P A^{*}=P A\left(P_{X A}, P_{X H}, W, V, \tau, \mu_{1}, \mu_{2}\right), \\
& S H^{*}=S H\left(P_{X A}, P_{X H}, W, V, \tau, \mu_{1}, \mu_{2}\right), \\
& S A^{*}=S A\left(P_{X A}, P_{X H}, W, V, \tau, \mu_{1}, \mu_{2}\right), \\
& R^{*}=R\left(P_{X A}, P_{X H}, W, V, \tau, \mu_{1}, \mu_{2}\right),
\end{aligned}
$$

where an asterisk $\left(^{*}\right)$ indicates that a given amount of time is optimal from the perspective of the decision-maker. ${ }^{6}$ The estimation of empirical counterparts to Eqs. (7)-(11) is the main goal of this paper.

We note that the specification of the utility function in Eq. (1) does not allow for direct utility effects of the time spent in eating and food preparation. This specification is consistent with Becker's (1965) original household production framework. However, it can be argued that not only do the food commodities themselves directly generate utility but possibly also the joy of eating and cooking. In that case, the specification of the utility function in Eq. (1) could be modified to include time in the food-related activities among the function's arguments. Namely, we could redefine utility as $\widetilde{U}=\widetilde{U}(F H, F A, Z, L, P H, S H, P A, S A, R ; \tau)$. Such a specification would be in line with Pollak and Wachter's (1975) modified household production framework. The remainder of the optimization problem's formulation and our approach to solve for the optimal time in the four types of eating and in food preparation would remain unchanged, however.

\section{Data}

\subsection{EH Module of ATUS and Analytical Sample}

We use data from the American Time Use Survey (ATUS), matched with the ATUS's Eating and Health (EH) Module, for the years 2006, 2007, and 2008 (see Hamrick 2010). The ATUS collects time-use information, including time in non-market activities such as eating, childcare, and various forms of leisure. ATUS respondents come from a subsample of households who participated in the Current Population Survey (CPS). We restrict the analysis to a sample of adults from single decision-maker households in part because data to rigorously investigate joint decisions on time allocation in multiple decision-maker households (e.g., married couples) are not available in

\footnotetext{
${ }^{6}$ The regularity conditions could include a requirement that the utility function and the food-commodity production functions be continuously differentiable and concave in their respective arguments.
} 
the ATUS. The ATUS collects time-use data from one individual per household on the respondent's activities that occurred on a "diary day" (a 24-hour period ending at 4 a.m. on the day of an interview). The ATUS also gathers information on the location of activities and identities of any other individuals present. During a calendar year, ATUS interviews are conducted continuously and corresponding diary days fall on different months of the year and days of the week. Demographic and socioeconomic characteristics are obtained through matching to CPS records (also, some characteristics are updated in the ATUS). For details on the survey design, see BLS (2012).

The ATUS records time-diary data for primary activities. If only one activity occurred during a particular period on the diary day, that activity is the primary activity for the period. If a respondent performed two or more activities concurrently, the respondent makes the choice as to which one to designate as the primary activity. The ATUS does not provide information on secondary activities (e.g., secondary eating), except in the case of childcare as a secondary activity. The EH Module was designed as a supplement to the "core” ATUS in 2006, 2007, and 2008-in order to collect data on secondary eating and drinking, among other information. Examples of secondary eating would be eating a hot dog while watching a baseball game or having coffee and donut during work time.

We pool ATUS/EH Module records from 2006, 2007, and 2008 (the empirical specification contains year dummies to control for potential survey design effects). This initial sample contains 37,914 respondents. We construct an analytical sample on its basis by applying restrictions consistent with the theoretical single decisionmaker model in Section 2 and include households comprised of a single adult (defined as an individual of age 18 years or older), with or without children of age 0-15 years present. We exclude from consideration households with two or more adults (e.g., married-couple households) and households with a child of age 16-17 years. Table 1 shows that after applying these restrictions, we obtain a sample of 11,187 respondents. An additional sample restriction is applied to account for data quality, with a record excluded if an ATUS interviewer believes that a respondent intentionally provided wrong answers, was unable to recall his or her activities, or deliberately reported unusually long durations. In total, the constructed analytical sample comprises 11,070 respondents.

\subsection{Dependent Variables}

Table 2 lists codes from the ATUS lexicon for the activities we group together and designate as "primary eating" and as "food preparation." Our definition of primary eating is similar to that of Hamrick et al. (2011). Our definition of food preparation is the same as that of Davis and You (2011) and includes food and drink preparation, presentation, and cleanup as well as grocery shopping and directly related travel.

In the "core" ATUS, primary eating and drinking is recorded as a "joint" activity: primary eating is not differentiated from primary drinking. In contrast, the EH Module treats secondary eating and secondary drinking as two distinct activities; they can occur during primary activities other than primary eating. Another feature of the EH Module's survey instrument is that secondary eating and secondary drinking may overlap during a given primary activity, but both will still be classified as "secondary" activities (rather than ranked as a secondary and a tertiary 
activity, for example). It is not always possible to quantify the overlap. In fact, the sum of time in secondary eating and time in secondary drinking can overstate the total time in secondary eating and drinking when viewed as a joint activity (i.e., similarly to primary eating and drinking). To construct a measure of time in secondary eating and drinking as a joint activity (henceforth, we refer to it simply as "secondary eating”), we implement a method suggested in the EH Module User's Guide to combine and use the longest duration activity (see Hamrick 2010). ${ }^{7}$

Also, we distinguish between eating at home and eating away from home, by using the activity location information in the ATUS. We classify eating as occurring "at home” if it takes place in the respondent's own home or yard, and "away from home" if it takes place elsewhere (at work, at a restaurant, in the car, and so on).

Table 3 presents summary statistics for the five dependent variables in our empirical analysis: (1) time in primary eating at home, (2) time in primary eating away from home, (3) time in secondary eating at home, (4) time in secondary eating away from home, and (5) time in food preparation. For each activity, we calculate its weighted mean duration (in minutes per day) using the EH Module's sample weights. We calculate standard errors of the mean estimates using the successive difference replication (SDR) method and the EH Module's replicate weights (for details, see BLS 2012, Ch. 7). The summary statistics are shown for the analytical sample as a whole as well as for selected subsamples: by gender (male and female), region (Northeast, Midwest, South, and West), and season (winter, spring, summer, and fall). ${ }^{8}$ The overall mean durations of the five activities range from 28.8 to 38.8 minutes per day. The mean durations conditioned on gender indicate that in comparison to women, men tend to spend less time in food preparation (45.7 minutes for women vs. 29.1 minutes for men) and more time in primary eating away from home (25.7 minutes for women vs. 33.1 minutes for men). Some differences in the mean durations are also seen with respect to region and season.

Table 4 reports the weighted percentage of observations with zero time in each of the four types of eating and in food preparation on the diary day (we provide estimates for the sample as a whole and for the same selected subsamples as in Table 3). A large fraction of the respondents report no time in secondary eating: $64.7 \%$ in the case of secondary eating at home and $69.3 \%$ in the case of secondary eating away from home. Also, more than half (52\%) report no time in primary eating away from home. We emphasize that roughly $99 \%$ of the respondents report positive time in at least one of the four types of eating. Notably, we do not drop from consideration the roughly $1 \%$ of the respondents in the sample with zero time in all four types of eating, but rather we include them in all estimations. We performed a sensitivity analysis by excluding them from the sample and re-estimating all empirical

\footnotetext{
${ }^{7}$ The steps of this procedure are as follows. First, for a given primary activity, we calculate the minimal possible duration of secondary eating and drinking (joint activity) as the maximum between the reported time in secondary eating and time in secondary drinking. This step assumes the largest possible overlap between secondary eating and secondary drinking. Second, we calculate the maximal possible duration by first summing the time in secondary eating with the time in secondary drinking and then taking the minimum between this sum and the time in the primary activity itself. This step assumes the smallest possible overlap. Third, we impute the time in secondary eating and drinking (joint activity) by taking the average of the calculated minimal and maximal durations.

${ }^{8}$ The term "season” refers to a calendar season (e.g., “winter” encompasses December, January, and February).
} 
equations. The obtained parameter estimates and calculated marginal effects (not reported here) are qualitatively identical and quantitatively similar to those discussed in this paper (i.e., based on the sample without the exclusion).

Another notable observation from Table 4 is that in comparison to women, men are more likely to report no time in food preparation on the diary day (32.1\% of women vs. $46.4 \%$ of men). The empirical analysis in Section 4 accounts for the fact that the data feature a substantial fraction of observations with zero time in an activity.

\subsection{Explanatory Variables: Prices}

To investigate effects of food prices on eating and food preparation time, we construct two food price measures. First, we employ Version 2 of the Quarterly Food-at-Home Price Database (QFAHPD-2), a publicly available source of estimates of food prices in the United States (for details, see Todd et al. 2010; Zhylyevskyy et al. 2013), and create a food-at-home price index. This index is constructed as an expenditure-weighted average of real food group prices (specific to geographical market area and year-quarter), where the weight of a food group represents annual U.S. expenditures on the group as a fraction of annual U.S. expenditures on all food groups in 2006. We convert nominal prices in the QFAHPD-2 into real prices using the Consumer Price Index (CPI) series (BLS 2013). The index data are merged with the respondent records according to the place of residence and date of the diary day, using a matching procedure similar to that of Gregory and Coleman-Jensen (2013). The specific geographical identifiers to implement the matching are obtained by linking the sample records to CPS files (see BLS 2012, Appendix K). Table 5 shows that, on average, the food-at-home price index value is 0.24 (real \$ per 100 grams of food as purchased).

Second, we create a fast food price index (see Chou et al. 2004; Powell 2009) based on data collected by the American Chamber of Commerce Researchers Association (ACCRA). It is calculated as an average of real prices (specific to metropolitan area and year-quarter) of three fast food items: (1) a McDonald's quarter-pounder hamburger with cheese, (2) an 11-12” thin crusted cheese pizza at Pizza Hut or Pizza Inn, and (3) fried chicken (thigh and drumstick) at Kentucky Fried Chicken or Church's. The index data are merged with the sample records according to the place of residence and date of the diary day. ${ }^{9}$ On average, the index value is 2.63 (real \$).

Because empirical time-use equations include a set of region, year, and season fixed effects (see Section 3.4), in order to avoid running into a severe multicollinearity problem we must first assess the extent to which the overall variation in the food price indices is accounted for by the region, year, and season indicator variables. We run an ordinary least squares (OLS) regression for each food price index on these indicators and use the $R^{2}$ value as a measure of the fraction of the overall variation in a price index "absorbed" by them. In the case of the food-athome index, the $R^{2}$ is $40.6 \%$. In the case of the fast food index, it is $28.7 \%$. Thus, while the region, year, and season

\footnotetext{
${ }^{9}$ In 2006-2008, the ACCRA collected data for roughly 400 different metropolitan areas. We match 6,278 sample respondents (out of 11,070) directly to a metropolitan area covered by the ACCRA. In the remaining cases, we merge a respondent's record with an average of the fast food price index values across metropolitan areas in the respondent's state of residence.
} 
indicators account for a non-negligible fraction of the overall variation in each food price index, there seems to be sufficient "left-over" variation present in order to include the price indices together with the indicators in the empirical time-use equations and estimate price effects.

Another potential problem with using food prices as explanatory variables is that they might be endogenous. In particular, in locations where residents have strong unobservable preference for eating away from home, the demand for fast food is likely to be high, which can lead to high fast food price values. ${ }^{10}$ While the potential for an endogeneity problem in our study seems limited because we analyze respondent-level time-use data rather than, for example, market-level food expenditure data, we choose to perform an additional investigation and test for the endogeneity of the fast food price index using an instrumental variable (IV) approach.

To construct an IV, we use information from the Occupational Employment Statistics dataset of the Bureau of Labor Statistics (BLS 2014). We extract the mean hourly wage (specific to metropolitan area and year) for an occupational code 35-3021 “Combined food preparation and serving workers, including fast food," convert it into real dollars using the CPI series, and merge the resulting real wage rate with the sample records according to the place of residence and date of the diary day. ${ }^{11}$ Table 5 shows that on average, the constructed wage variable, referred to as “food worker mean wage," is 3.87 (real \$ per hour). The main idea underlying this IV is that the food worker wage represents a supply-side factor affecting the price of fast food (but not a demand-side factor). Additionally performed analyses suggest that it is a strong instrument in the case of our sample. Namely, in "first-stage" OLS regressions of the fast food price index on this wage variable and other variables (we investigated several specifications), the coefficient estimate on the wage variable is always positive and statistically significant. Moreover, the "first-stage" $F$ statistics always exceed 150, which is well above a recommended minimal value of 10, according to Stock and Yogo's (2005) rule of thumb to judge an IV to be strong.

To test for the endogeneity of the fast food price index, we estimate a series of IV Tobit models (Newey 1987) for the reported times in eating and food preparation (we consider each time-use activity separately and estimate specifications both with and without region, year, and season fixed effects). The specification is similar to that of Tobit models discussed in Section 4, except that in addition to a time-use equation, an IV Tobit model

\footnotetext{
${ }^{10}$ The ACCRA-based fast food price index is calculated at the metropolitan area level, and the ACCRA database covers roughly 400 metropolitan areas across the United States. In comparison, the QFAHPD-based food-at-home price index is calculated at a more broadly defined "geographical market area" level, as the QFAHPD partitions the country into only 35 areas in total (for a map, see Todd et al. 2010, Figure 1 on p. 13). Since the food-at-home index is available at a higher level of geographical aggregation than the fast food index, the food-at-home index values are relatively less likely to be driven by localized food preference effects. As such, we believe that in comparison to the case of the fast food index, the potential for endogeneity of the food-at-home index in our empirical analysis should be relatively low. In addition, we note that the estimated empirical equations include the set of region, year, and season fixed effects, which should help to account for unobservable factors (e.g., regional differences in food and time-use preferences) that can simultaneously affect food-related time use and food prices.

${ }^{11}$ The level of geographical specificity of the wage data coincides with that of the fast food price data (i.e., by metropolitan area).
} 
includes a second equation in which the fast food price index is instrumented using the food worker mean wage. A non-zero correlation between the error terms of the time-use and fast food price index equations would indicate the endogeneity of the price index (conversely, no correlation would suggest that the price index is exogenous). In Wald tests performed after estimating the IV Tobit models, the $p$-value of a null hypothesis of no correlation ranges from 0.21 to 0.99 (depending on the specification estimated). Thus, the exogeneity of the fast food price index cannot be rejected at a conventional significance level. We also conduct Hausman (1978) specification tests. Under the null hypothesis, the fast food price index is exogenous, and both the Tobit and IV Tobit estimates are consistent but Tobit estimates are more efficient (under the alternative hypothesis, the price index is endogenous and only the IV Tobit estimates are consistent). The resulting $p$-values range from 0.23 to 0.99 , which again suggests that the price index is exogenous. Overall, this investigation fails to generate evidence against the exogeneity of food prices in the specific context of our study. Thus, we choose to treat the respondents in the sample as price takers and include the food price indices as explanatory variables in the estimated time-use equations.

\subsection{Explanatory Variables: Respondent Characteristics and Diary Day Attributes}

We employ conventional demographic and socioeconomic characteristics such as age, gender, etc., as well as a range of attributes of the diary day. As shown in Table 5, the individuals comprising the sample are on average 52 years old, $42 \%$ are male, $78 \%$ are white, and $8 \%$ are Hispanic. We include an indicator for foreign-born respondents ( $9 \%$ of the sample) because they may have different preferences regarding eating away from home and food preparation than the U.S.-born respondents. In addition, we include the log of real annual family income to control for differences in the purchasing power across households, which may influence time use. Nominal income is set at the midpoint of the reported income bracket and converted into real dollars using the CPI series (BLS 2013). If nominal income is missing (15\% of the sample), we include an indicator for missing income and set the log of real family income to zero. Also, we employ two poverty indicators: one for respondents with household income below $130 \%$ of the federal poverty line, and the other for those with income between $130 \%$ and $185 \%$ of the poverty line. The thresholds correspond to income cutoffs defining one's eligibility to participate in food assistance programs such as the Supplemental Nutrition Assistance Program (SNAP: 130\% of the poverty level) and Special Supplemental Nutrition Program for Women, Infants, and Children (WIC: 185\% of the poverty level). It should be noted that the income and poverty measures are based on reported income over the twelve months preceding the CPS interview with the respondent's household; as such, they are predetermined when food-related time allocations are made on the ATUS diary day. Next, over half of the respondents have at least some college education (the education dummies employed in the analysis represent the highest level of educational attainment), and more than four-fifths (82\%) reside in a metropolitan area. In addition, we include indicators for the presence of children of age 0-5 years and age 6-15 years (some households may have children in both age categories present). We distinguish between these age categories because caring for younger children could differentially affect the utility derived from 
eating at home vs. away from home, for example. Also, we expect the presence of children to be associated with more time in food preparation. Note that younger children can differentially affect food preparation time vs. older children, because older children might take over some of the food preparation tasks of adults (e.g., setting the table).

We use detailed controls for the diary day. Day-of-the-week dummies are included because time in eating and food preparation may systematically vary over the course of a week due to cultural practices or differential opportunity cost of time. To illustrate, individuals may be more likely to eat away from home on certain days (e.g., on Friday), and engage in more food preparation on other days (e.g., on the weekend). Also included is an indicator for a holiday (New Year's Day, Easter, Memorial Day, Fourth of July, Labor Day, Thanksgiving, or Christmas). Cultural practices and business closures may encourage (i.e., decrease the opportunity cost of time in) home- and family-centered activities such as food preparation on holidays.

We also create and include in the estimated empirical equations a set of region, year, and season indicators (fixed effects). Controlling for a household's region of residence (Northeast, Midwest, South, or West) may help to account for possible geographical differences in preferences regarding time use, for example. Year (2006, 2007, or 2008) indicators may help to control for survey design effects and for possible impact of macroeconomic shocks. In turn, the indicators for season (winter, spring, summer, or fall) may help to account for variation in time-use patterns due to systematic weather differences across seasons, as an example. Notably, because the food-at-home and fast food price indices are correlated with the indicators for region, year, and season, the inclusion of region, year, and season fixed effects in the empirical equations makes us more confident that computed estimates on the price indices represent price effects, rather than pick up effects of the listed, potentially confounding factors (i.e., geographical differences in preferences, survey design effects, weather seasonality, and so on). We performed a sensitivity analysis by re-estimating all econometric models without including the region, year, or season fixed effects in the empirical equations. The re-estimation results (not reported here) are very similar to those presented in this paper (i.e., those obtained with the fixed effects included), except that marginal effect estimates for the food-at-home price index tend to be larger in magnitude in the case of eating activities.

\section{Econometric Approach}

Section 3.2 has shown that a non-negligible fraction of the respondents report zero time in a particular type of eating, especially in the case of secondary eating, or in food preparation on the diary day. Thus, an OLS approach is not appropriate for modeling duration of these activities. As an alternative to OLS, we first investigate using a Tobit approach (Tobin 1958; Amemiya 1984). However, it is well known that the Tobit model has limitations. For example, it assumes that error terms are homoscedastic and normally distributed; a violation of these assumptions would result in an inconsistent estimator. ${ }^{12}$ Moreover, it assumes that the same process underlies the probability of a

\footnotetext{
${ }^{12}$ Cameron and Trivedi (2010, p. 550) recommend using Lagrange multiplier (LM) tests of heteroscedasticity and nonnormality for the Tobit model because these tests only require estimating the model under the null hypothesis of homoscedasticity and normality. We implement such testing and discuss the results in Section 5.1.
} 
zero value and the magnitude of a positive value. Two-part, or hurdle, models can provide a better fit to the data by relaxing the Tobit assumptions; in particular, hurdle models allow for the possibility that the zero and positive values are generated by different processes (Cameron and Trivedi 2010, p. 553; for a discussion of two-part models, see also Manning et al. 1987). More specifically, we choose to employ the double-hurdle model of Cragg (1971) and compare its estimates to those from the Tobit approach. Using simulated time-diary data, Stewart (2013) shows that the double-hurdle model can perform significantly better than the Tobit model. Also, the previous literature has employed the double-hurdle model to investigate food preparation time (e.g., Möser 2010).

We adopt notation similar to that of Huang (2001) and Burke (2009). Let $i$ index the respondents: $i=1$, $2, \ldots, n$, where $n$ is their total number (in our case, $n=11,070$ ). Also, let $j$ index the five time-use activities: $j=1$ is primary eating at home, $j=2$ is primary eating away from home, $j=3$ is secondary eating at home, $j=4$ is secondary eating away from home, and $j=5$ is food preparation. We denote the time (in minutes per day) reported by respondent $i$ in activity $j$ by $y_{i j}$ (note that $y_{i j}$ could be either positive or zero). In addition, let $x_{i}$ be a vector comprising a constant term and the variables representing the food prices, individual characteristics, and attributes of the diary day for respondent $i$, as described in Sections 3.3 and 3.4. While $x_{i}$ does not contain the wage rate (many respondents in the sample are not working and we do not observe the wage rate for them), it includes individual characteristics such as age, education, etc. that can proxy for the reservation wage.

In the case of the Tobit approach, we model $y_{i j}$ using a latent variable $y_{i j}^{*}$ that is described by an equation

$$
y_{i j}^{*}=x_{i}^{\prime} \beta_{j}+\varepsilon_{i j}
$$

and linked to the observed time $y_{i j}$ as follows:

$$
y_{i j}=y_{i j}^{*} \text { if } y_{i j}^{*}>0 \text {, and } y_{i j}=0 \text { if } y_{i j}^{*} \leq 0 .
$$

In Eq. (12), $\beta_{j}$ is a coefficient vector (specific to activity $j$ ) and $\varepsilon_{i j}$ is a mean-zero, normally distributed error term (specific to respondent $i$ and activity $j$ ), $\varepsilon_{i j} \mid x_{i} \sim$ i.i.d. $N\left(0, \sigma_{j}^{2}\right) .{ }^{13}$ The likelihood contribution for respondent $i$ is

$$
L_{i}\left(y_{i j} \mid x_{i}\right)=\left[1-\Phi\left(\frac{x_{i}^{\prime} \beta_{j}}{\sigma_{j}}\right)\right]^{1\left(y_{i j}=0\right)} \cdot\left[\frac{1}{\sqrt{2 \pi} \sigma_{j}} \exp \left\{-\frac{\left(y_{i j}-x_{i}^{\prime} \beta_{j}\right)^{2}}{2 \sigma_{j}^{2}}\right\}\right]^{1\left(y_{i j}>0\right)},
$$

where $\Phi(\cdot)$ is the standard normal cumulative distribution function and $1(\cdot)$ is the indicator function, which takes the value of one if a specified condition is true and the value of zero otherwise.

A key limitation of the Tobit model is that its "discrete part," which represents the choice between $y_{i j}=0$ and $y_{i j}>0$, and its "continuous part," which explains the magnitude of $y_{i j}$ given $y_{i j}>0$, share the same influencing variables with the same coefficient effects $\left(\beta_{j}\right)$. However, the effects may differ in practice. For

\footnotetext{
${ }^{13}$ Here, we investigate each of the five time-use activities separately. As noted in Section 5.1, however, we also consider a seemingly unrelated regression (SUR) Tobit model, in which the error terms for respondent $i$ are allowed to be correlated across the time-use activities. In this SUR Tobit model, the time-use equations are estimated jointly as a system. Zellner (1962) and Srivastava and Giles (1987) provide details on the SUR approach.
} 
instance, consider the respondent's gender. Men may be less likely than women to eat at home. However, when individuals eat at home, there need not be a difference between men and women in terms of eating duration (if all else is equal). The double-hurdle model (see Cragg 1971, equations [7] and [9] on p. 831) addresses the limitation. To be more precise, we write the likelihood contribution for respondent $i$ in the case of the double-hurdle model as:

$$
\tilde{L}_{i}\left(y_{i j} \mid x_{i}\right)=\left[1-\Phi\left(x_{i}^{\prime} \gamma_{j}\right)\right]^{1\left(y_{i j}=0\right)} \cdot\left[\frac{1}{\sqrt{2 \pi} \sigma_{j}} \exp \left\{-\frac{\left(y_{i j}-x_{i}^{\prime} \beta_{j}\right)^{2}}{2 \sigma_{j}^{2}}\right\} \frac{\Phi\left(x_{i}^{\prime} \gamma_{j}\right)}{\Phi\left(x_{i}^{\prime} \beta_{j} / \sigma_{j}\right)}\right]^{1\left(y_{i j}>0\right)},
$$

where $\gamma_{j}$ is an additional coefficient vector (specific to activity $j$ ). Here, the probability of $y_{i j}=0$ and the magnitude of a positive $y_{i j}$ are determined by different processes. Importantly, the Tobit model is nested within the double-hurdle model: if $\gamma_{j}=\beta_{j} / \sigma_{j}$, Eq. (15) reduces to Eq. (14). This property allows us to implement a likelihood ratio (LR) test of the applicability of the Tobit model to describe the time-use data vs. the less restrictive approach offered by the double-hurdle model (see Section 5.1 for the test results). Both models are estimated using the maximum likelihood method. Standard errors are clustered at the state level.

The coefficient vectors $\beta_{j}$ and $\gamma_{j}$ are specified on a latent variable scale and can be difficult to interpret. To facilitate the interpretation of the estimates and a comparison of corresponding Tobit and double-hurdle model results, we compute and report average marginal effects. In particular, we calculate a vector of average marginal effects of the explanatory variables on the probability of a positive activity duration, $\frac{1}{n} \sum_{i=1}^{n} \frac{\partial}{\partial x_{i}} \operatorname{Pr}\left[y_{i j}>0 \mid x_{i}\right]$, and a vector of marginal effects on expected activity duration, $\frac{1}{n} \sum_{i=1}^{n} \frac{\partial}{\partial x_{i}} \mathrm{E}\left[y_{i j} \mid x_{i}\right]$. In the case of the latter vector, the magnitude of a marginal effect represents an average change in the expected duration of a given eating or food preparation activity $(j)$ associated with a unit change in an explanatory variable—specified in minutes per day; these marginal effects account for the fact that the time devoted to the activity cannot be negative. Analytical formulas for marginal effects for the Tobit and double-hurdle models can be found in Greene (2012, pp. 848-850) and Burke (2009, pp. 586-587), respectively.

\section{Results}

\subsection{Comparison of Estimated Models}

Tables 6 and 7 show the average marginal effects of the explanatory variables on the probability of a non-zero (i.e., positive) time in each of the five eating and food preparation activities for the estimated Tobit and double-hurdle models, respectively. Tables 8 and 9 list the average marginal effects on the expected duration of the activities in minutes per day (again, for the Tobit and double-hurdle models, respectively). While the direction of the two types of marginal effects is identical for Tobit because it assumes that the same process underlies the decisions on whether to engage in an activity and on how much time to devote to it, we include both Tables 6 and 8 so as to facilitate a comparison to the corresponding double-hurdle model results in Tables 7 and 9. The empirical time-use equations, 
on which the marginal effects are based, are estimated for each activity separately. ${ }^{14}$

The results of the two modeling approaches differ somewhat. For instance, higher fast food prices are found to increase the probability of secondary eating at home (at the $1 \%$ significance level) in the case of the double-hurdle model (see Table 7), but the analogous Tobit marginal effect (Table 6) is smaller in magnitude and not statistically significant. As another example, consider day-of-the-week effects on the expected duration of primary eating away from home. The estimate for Saturday is positive and statistically significant for the doublehurdle model (Table 9), but is smaller and not significant for the Tobit model (Table 8). Still, differences between the Tobit and double-hurdle models' marginal effects are small in magnitude in many other instances. ${ }^{15}$

We also report the results of specification testing. The last row of Table 6 lists the test statistic values and bootstrapped 1\% critical values for LM tests of the null hypothesis of normality and homoscedasticity of Tobit error terms and linearity of the Tobit model's latent variable in the explanatory variables. ${ }^{16}$ This null hypothesis of the validity of Tobit assumptions is rejected at the $5 \%$ significance level in the case of primary eating away from home (a bootstrapped 5\% critical value, not reported in the table, is 3.86) and rejected at the $1 \%$ level in the case of the other four activities. In turn, the last row of Table 7 shows the results from LR tests of the applicability of Tobit to describe the data vs. the less restrictive approach offered by the double-hurdle model (recall that Tobit is nested within the double-hurdle model). Tobit is strongly rejected in all instances. Thus, we choose to focus on the estimates from the double-hurdle modeling approach (Tables 7 and 9) in the remainder of this section.

\subsection{Price Effects}

Food prices are found to influence the pattern of eating and food preparation. In particular, higher food-at-home prices are associated with an increased probability of primary eating at home (Table 7). Also, respondents facing higher food-at-home prices spend more time in primary eating at home and food preparation (Table 9). These results suggest that higher food-at-home prices do not tend to result in a significant shift toward eating away from home, but rather lead to more time in food preparation—as would be the case of using products with less embedded convenience, for example — and with that increased food preparation, to also more time in primary eating at home. In addition, the estimates indicate that individuals residing in places with higher fast food prices are more likely to engage in secondary eating at home and food preparation (Table 7). We also find that higher fast food prices are associated with more time in food preparation, but less time in primary eating at home (Table 9). While

\footnotetext{
${ }^{14}$ The theoretical time-use Eqs. (7)-(11) suggest that the times in the five eating and food preparation activities for a respondent can be affected by the same unobservable factors. In that case, we can expect the error terms of the corresponding empirical equations to be correlated with each other. To explore this possibility, we used the CMP package of Roodman (2011) and estimated the five time-use Tobit equations jointly as a SUR system. While the estimates indicate non-zero correlations between the error terms, average marginal effects computed for the SUR Tobit model are practically indistinguishable from those reported in Tables 6 and 8.

${ }^{15}$ In addition to the variables listed in the tables, each estimated equation includes a constant term and the region, year, and season dummies. To save space, marginal effects for these dummies are not reported.

${ }^{16}$ Critical values for these LM tests are obtained using a parametric bootstrap procedure of Drukker (2002) in order to reduce possible test size distortions.
} 
the latter effect is not in the expected direction, purchasing fast food products for consumption at home (e.g., frozen pizza to prepare at home instead of going out for pizza) may be an important use of fast food type products, and as such, may affect the time devoted to primary eating at home. ${ }^{17}$ Overall, we conclude that food prices affect home production and time allocation decisions.

\subsection{Other Effects}

We find statistically significant effects associated with the household financial resources. Income effects are relatively strong and intuitive. To illustrate, additional income is linked to a higher probability of engaging in primary and secondary eating away from home and a lower probability of engaging in food preparation and primary eating at home (Table 7). Additional income is also associated with more time in eating away from home and less time in eating at home (Table 9). Moreover, our estimates show that respondents with low income and income near the poverty line (less than $130 \%$ of the poverty level and between $130 \%$ and $185 \%$ of the poverty level) are less likely to eat away from home. Also, low income ( $<130 \%$ poverty) is associated with a higher probability of food preparation and primary eating at home. In addition, respondents with low income and income near the poverty line tend to spend more time in food preparation and primary eating at home. For example, being in a household with income below $130 \%$ of the poverty level is associated with 5.30 more minutes per day in food preparation, while being in a household between $130 \%$ and $185 \%$ of the poverty level is associated with 3.72 additional minutes in food preparation—compared to the reference group of individuals with household income above $185 \%$ of the poverty level. Also, low-income respondents ( $<130 \%$ poverty) spend less time in primary and secondary eating away from home and more time in secondary eating at home. The direction of the estimates indicates that individuals with fewer financial resources may substitute eating at home for (the relatively more expensive option of) eating away from home. Moreover, consistent with the existing literature (e.g., Aguiar and Hurst 2005), our estimates suggest that lower income individuals may substitute time for monetary expenditures in the food preparation process (e.g., by purchasing products with less embedded time savings or spending more time in food shopping to find good deals).

Most of the results for demographic variables are intuitive. Older respondents spend more time in eating at home, but less time in eating away from home than younger respondents do. ${ }^{18}$ Also, we estimate that older respondents spend more time in food preparation, which is consistent with findings of Aguiar and Hurst $(2005 ; 2007)$ and Tashiro (2009) and could be due to older individuals (e.g., retirees) having a lower opportunity cost of time. In addition, it is possible that older individuals use more basic ingredients and "raw" foods but fewer pre-prepared (“convenience”) foods due to their greater knowledge of cooking methods.

In comparison to women (the reference gender group), men are less likely to engage in primary eating at

\footnotetext{
${ }^{17}$ It should be noted that the effect is only marginally statistically significant here (at the $10 \%$ level) and is not statistically significant in an empirical model that does not include the region, year, and season fixed effects.

${ }^{18}$ These effects may reflect differences in time-use preferences across the age cohorts, rather than reflect age effects per se. In a cross-sectional study such as ours, disentangling cohort effects from age effects is not possible.
} 
home, secondary eating at home and away from home, and food preparation, but more likely to engage in primary eating away from home. Moreover, men devote more time to primary eating away from home and substantially less time to food preparation. To be more specific, being male is associated with 10.58 minutes less (per day) in food preparation, which constitutes $27 \%$ of the average daily duration of this activity $\left(27 \% \cong \frac{10.58}{38.8} \cdot 100 \%\right.$; see Table 3 for average activity durations). Our finding is in line with the results reported by Mancino and Newman (2007).

Relative to whites (the reference racial group), African Americans are less likely to engage in all types of eating and in food preparation, while respondents of "other race” are less likely to engage in secondary eating at home and away from home and in food preparation. Moreover, being African American is associated with less time in primary eating at home and away from home and less time in secondary eating away from home. Hamermesh (2010) reports a similar result in that whites tend to spend more time in primary eating (Hamermesh does not differentiate between eating at home vs. away from home, however). In addition, we find that individuals of "other race" tend to spend more time in primary eating at home and food preparation.

Ethnic and cultural factors affect time use. Relative to non-Hispanics (the reference category), Hispanic respondents are less likely to engage in primary eating at home and in secondary eating at home and away from home, but are more likely to do primary eating away from home. Also, Hispanics devote less time to primary eating at home and to secondary eating at home and away from home. Compared to U.S.-born respondents (the reference category), those who are foreign-born are less likely to do secondary eating at home and away from home, but are more likely to engage in primary eating at home and food preparation. In addition, being foreign-born is associated with less time in secondary eating at home and away from home and with more time in primary eating at home and food preparation. The latter could be because foods and raw ingredients that cater to specific food tastes and preferences of foreignborn individuals are less readily available locally and require additional food shopping time.

Educational background and household composition are also estimated to influence time use. Compared to respondents without a high school diploma (the reference category), those with more education (i.e., high school diploma or more) are more likely to engage in primary eating away from home and in secondary eating at home and away from home. Also, higher educated respondents devote more time to eating away from home. These results could be due to such respondents being more likely to work outside of the home. The presence of children of age $0-5$ years in the household is associated with a lower likelihood of and less time in primary eating away from home. In turn, the presence of children of age 6-15 years is linked to a higher probability of and more time in primary and secondary eating at home and to a lower likelihood of and less time in primary eating away from home. These results suggest that the relative value of (i.e., utility derived from) time in primary eating away from home may be lower if children are present. In addition, the presence of children is strongly associated with a higher incidence of and more time devoted to food preparation, which is consistent with the findings of Mancino and Newman (2007).

Lastly, we estimate several effects related to the diary day attributes. For example, the duration of food 
preparation is significantly longer on a holiday (by 12.77 minutes). Also, time use can vary over the course of the week. To illustrate, compared to Wednesday (the reference category), respondents spend more time in secondary eating at home and less time in secondary eating away from home on Sunday. As another example, primary eating away from home tends to last longer on Friday. These differences in eating time are accompanied by differences in food preparation time. For instance, respondents tend to decrease food preparation time on Friday but increase it on Saturday and Sunday. These and other estimated day-of-the-week effects are intuitive. In particular, many individuals would traditionally go out after work and do less food preparation on Friday, but would spend more time in home production activities including food preparation and in home-centered leisure activities often accompanied by secondary eating (e.g., snacking while watching TV) on the weekend. ${ }^{19}$

\section{Discussion and Conclusion}

Among the many social and economic changes in the last several decades, changes in the use of time and structure of activities related to eating are some of the most significant ones and have implications for individual health and public policies targeting food-related behaviors. The decline in food preparation at home and the shift away from the traditional meal pattern (i.e., breakfast, lunch, and dinner) — toward snacking and eating during other activities and toward eating away from home--have altered the nature of food consumption in the United States. The market has responded through increased availability of pick-up snacks and foods. Previous research has shown that the pattern of eating can affect health. These changes and their consequences underscore the importance of a comprehensive investigation of food-related time use in the household.

We focus on the behavior of single adults, with or without related children under the age of sixteen present in the household. Our research adds to the literature by incorporating into the model the individual's ability to substitute time across eating activities differentiated by type (primary vs. secondary) and further differentiated by location (at home vs. away from home). Additional insight is gained by also studying food preparation time. Notably, the empirical estimates suggest that food prices can influence the pattern of time use. For example, higher food-at-home prices are associated with more time in food shopping and meal preparation. Thus, changes in the retail prices of food and changes in public policies affecting food prices (e.g., through taxes and subsidies) can impact home production decisions and food-related time use, and have subsequent effects on eating patterns and health. Our price effects' estimates are novel and provide new information on the role of food prices in the allocation of time in the household that can help guide public policy.

In addition, we find that the allocation of time is influenced by individual socioeconomic characteristics

\footnotetext{
${ }^{19}$ While not reported in the tables, our marginal effect estimates also indicate a longer duration of secondary eating for the years 2007 and 2008 compared to 2006. In part, this finding may be attributed to a positive time trend in the duration of secondary eating pointed out by Hamrick (2010). However, it is more likely due to a survey design effect, because the $2007 \mathrm{EH}$ Module introduced an "all day" response option for secondary eating and drinking activities, which can increase the calculated time in secondary eating using our approach in Section 3.2.
} 
and household composition. To illustrate, low-income adults spend more time in food preparation and primary eating at home and are less likely to eat away from home than those with more income. Overall, the estimates are consistent with lower-income individuals utilizing time-intensive strategies aimed at reducing monetary expenditures related to food consumption, including efforts to reduce prices paid through devoting more time to food shopping and meal preparation (Leibtag and Kaufman 2003; Aguiar and Hurst 2007). Also, the presence of children in the household is associated with more time in food preparation and less time in primary eating away from home. Vickery (1977) and others argue that public assistance programs pay little attention to time-use differentials across different household types and understate the role of time constraints faced by single individuals, especially those with children. Our results for time use underscore this concern. While more time in food preparation and eating at home can positively affect health (Kolodinsky and Goldstein 2011), the difficulty for low-income single adults with children to devote extra time to preparing at-home meals that meet dietary guidelines and have relatively low cost (e.g., meals consistent with the Thrifty Food Plan) can be a limiting factor in achieving a healthier diet (Davis and You 2011).

We draw several implications. The differences in the eating and food preparation time patterns across the socioeconomic groups, and as influenced by the price of food, are statistically significant and suggest the need to better understand the consequences of these differences for dietary intake, energy balance, and health. While there is some evidence indicating that a higher eating frequency is associated with a lower risk of obesity (Hamermesh 2010), there is also evidence that the shift away from the traditional meal consumption pattern toward snacking and eating as a secondary activity can result in increased caloric intake, especially as it comes in the form of snacks that have become more energy-dense. Public policies and programs that are designed to provide foods for at-home use (as an example, SNAP) will be most effective when accounting for the varied kinds of eating environments as well as for the growing importance of secondary eating time and for declining food preparation time. Since the presence of children in low-income, single adult households already shifts time use toward food preparation, public policies attempting to affect a further increase in food preparation among such households—as a way to indirectly improve health outcomes, for example - need to account for the limited opportunities these households can have to acquire and prepare healthier foods when additional time is required. The recognition of the critical role today of secondary eating time, including secondary eating time away from home, underscores the need to more directly address through public policy and nutrition education the opportunities and choices regarding eating that occur throughout the day and in alternative locations.

\section{Acknowledgements}

Funding for this research was provided in part by the U.S. Department of Agriculture award \#2012-70002-19386 to the Center for Agricultural and Rural Development at Iowa State University. The authors declare that they have no conflict of interest. 


\section{References}

Aguiar, M ., \& Hurst, E. (2005). Consumption versus expenditure. Journal of Political Economy, 113, 919-948.

Aguiar, M., \& Hurst, E. (2007). Prices and production. American Economic Review, 97, 1533-1559.

Amemiya, T. (1984). Tobit models: A survey. Journal of Econometrics, 24, 3-61.

Becker, G. (1965). A theory of the allocation of time. Economic Journal, 75, 493-517.

Bellisle, F., \& Dalix, A.-M. (2001). Cognitive restraint can be offset by distraction, leading to increased meal intake in women. American Journal of Clinical Nutrition, 74, 197-200.

Bertrand, M., \& Whitmore Schanzenbach, D. (2009). Time use and food consumption. American Economic Review, 99, 170-176.

Biddle, J.E., \& Hamermesh, D.S. (1990). Sleep and the allocation of time. Journal of Political Economy, 98, 922-943.

Bureau of Labor Statistics (BLS) (2012). American Time Use Survey user's guide: Understanding ATUS 2003 to 2011. Washington, DC: BLS and U.S. Census Bureau. Available at http://www.bls.gov/tus/atususersguide.pdf (last accessed on May 7, 2013).

Bureau of Labor Statistics (BLS) (2013). Consumer Price Index: All urban consumers. Available at ftp://ftp.bls.gov/pub/special.requests/cpi/cpiai.txt (last accessed on May 7, 2013).

Bureau of Labor Statistics (BLS) (2014). Occupational Employment Statistics data. Available at http://www.bls.gov/oes/tables.htm (last accessed on April 23, 2014).

Burke, W.J. (2009). Fitting and interpreting Cragg's tobit alternative using Stata. Stata Journal, 9, 584-592.

Cameron, A.C., \& Trivedi, P.K. (2010). Microeconometrics using Stata, revised ed. College Station, TX: Stata Press.

Chiappori, P.-A. (1997). Introducing household production in collective models of labor supply. Journal of Political Economy, 105, 191-209.

Chou, S.-Y., Grossman, M., \& Saffer. H. (2004). An economic analysis of adult obesity: Results from the Behavioral Risk Factor Surveillance System. Journal of Health Economics, 23, 565-587.

Cragg, J.G. (1971). Some statistical models for limited dependent variables with application to the demand for durable goods. Econometrica, 39, 829-844.

Cutler, D.M., Glaeser, E.L., \& Shapiro, J.M. (2003). Why have Americans become more obese? Journal of Economic Perspectives, 17, 93-118.

Dauphin, A., El Lahga, A.-R., Fortin, B., \& Lacroix, G. (2011). Are children decision-makers within the household? Economic Journal, 121, 871-903.

Davis, G.C. (2013). Food at home production and consumption: Implications for nutrition quality and policy. Review of Economics of the Household (in press); DOI: 10.1007/s11150-013-9210-0.

Davis, G.C., \& You, W. (2011). Not enough money or not enough time to satisfy the Thrifty Food Plan? A cost difference approach for estimating a money-time threshold. Food Policy, 36, 101-107.

Douthitt, R.A. (2000). “Time to do the chores?” Factoring home-production needs into measures of poverty. Journal of Family and Economic Issues, 21, 7-22.

Drukker, D.M. (2002). Bootstrapping a conditional moments test for normality after tobit estimation. Stata Journal, 2, 125-139.

Greene, W.H. (2012). Econometric analysis, 7th ed. Upper Saddle River, NJ: Prentice Hall.

Gregory, C.A., \& Coleman-Jensen, A. (2013). Do high food prices increase food insecurity in the United States? Applied Economic Perspectives and Policy, 35, 679-707.

Gronau, R. (1977). Leisure, home production, and work: The theory of the allocation of time revisited. Journal of Political Economy, 85, 1099-1123.

Hamermesh, D.S. (2007). Time to eat: Household production under increasing income inequality. American Journal of Agricultural Economics, 89, 852-863.

Hamermesh, D.S. (2010). Incentives, time use and BMI: The roles of eating, grazing and goods. Economics and Human Biology, 8, 2-15.

Hamrick, K.S. (2010). Eating and Health Module user’s guide. Administrative Publication No. 47. Washington, DC: ERS, USDA.

Hamrick, K.S., Andrews, M., Guthrie, J., Hopkins, D., \& McClelland, K. (2011). How much time do Americans spend on food? Economic Information Bulletin No. 86. Washington, DC: ERS, USDA.

Hausman, J.A. (1978). Specification tests in econometrics. Econometrica, 46, 1251-1271.

Howarth, N.C., Huang, T.T.-K., Roberts, Lin, B.-H., \&. McCrory, M.A. (2007). Eating patterns and dietary composition in relation to BMI in younger and older adults. International Journal of Obesity, 31, 675-684.

Huang, H.-C. (2001). Bayesian analysis of the SUR Tobit model. Applied Economics Letters, 8, 617-622. 
Kalenkoski, C.M., \&. Hamrick, K.S. (2013). How does time poverty affect behavior? A look at eating and physical activity. Applied Economic Perspectives and Policy, 35, 89-105.

Kolodinsky, J.M., \& Goldstein, A.B. (2011). Time use and food pattern influences on obesity. Obesity, 19, 23272335.

Leibtag, E.S., \& Kaufman, P.R. (2003). Exploring food purchase behavior of low-income households: How do they economize? Agriculture Information Bulletin No. 747-07. Washington, DC: ERS, USDA.

Lin, B.-H., \& Guthrie, J. (2012). Nutritional quality of food prepared at home and away from home, 1977-2008. Economic Information Bulletin No. 105. Washington, DC: ERS, USDA.

Ma, Y., Bertone, E.R., Stanek III, E.J., Reed, G.W., Hebert, J.R., Cohen, N.L., Merriam, P.A., \& Ockene, I.S. (2003). Association between eating patterns and obesity in a free-living US adult population. American Journal of Epidemiology, 158, 85-92.

Mancino, L., \& Newman, C. (2007). Who has time to cook: How family resources influence food preparation. Economic Research Report No. 40. Washington, DC: ERS, USDA.

Manning, W.G., Duan, N., \& Rogers, W.H. (1987). Monte Carlo evidence on the choice between sample selection and two-part models. Journal of Econometrics, 35, 59-82.

Möser, A. (2010). Food preparation patterns in German family households. An econometric approach with time budget data. Appetite, 55, 99-107.

Newey, W.K. (1987). Efficient estimation of limited dependent variable models with endogenous explanatory variables. Journal of Econometrics, 36, 231-250.

Pollak, R.A., \& Wachter, M.L. (1975). The relevance of the household production function and its implications for the allocation of time. Journal of Political Economy, 83, 255-278.

Poothullil, J.M. (2002). Role of oral sensory signals in determining meal size in lean women. Nutrition, 18, 479-483.

Popkin, B.M., \& Duffey, K.J. (2010). Does hunger and satiety drive eating anymore? Increasing eating occasions and decreasing time between eating occasions in the United States. American Journal of Clinical Nutrition, 91, $1342-1347$.

Powell, L.M. (2009). Fast food costs and adolescent body mass index: Evidence from panel data. Journal of Health Economics, 28, 963-970.

Roodman, D.M. (2011). Estimating fully observed recursive mixed-process models with CMP. Stata Journal, 11, 159-206.

Srivastava, V.K., \& Giles, D.E. (1987). Seemingly unrelated regression equations models: Estimation and inference. New York: Dekker.

Stewart, J. (2013). Tobit or not Tobit? Journal of Economic \& Social Measurement, 38, 263-290.

Stock, J.H., \& Yogo, M. (2005). Testing for weak instruments in linear IV regression. In Identification and inference for econometric models, Andrews, D.W.K., \& Stock, J.H. (eds.), pp. 80-108. New York, NY: Cambridge University Press.

Tashiro, S. (2009). Differences in food preparation by race and ethnicity: Evidence from the American Time Use Survey. Review of Black Political Economy, 36, 161-180.

Tobin, J. (1958). Estimation of relationships for limited dependent variables. Econometrica, 26, 24-36.

Todd, J.E., Mancino, L., Leibtag, E., \& Tripodo, C. (2010). Methodology behind the Quarterly Food-at-Home Price Database. Technical Bulletin No. 1926. Washington, DC: ERS, USDA.

Vickery, C. (1977). The time-poor: A new look at poverty. Journal of Human Resources, 12, 27-48.

You, W., \& Davis, G.C. (2010). Household food expenditures, parental time allocation, and childhood overweight: An integrated two-stage collective model with an empirical application and test. American Journal of Agricultural Economics, 92, 859-872.

Zellner, A. (1962). An efficient method of estimating seemingly unrelated regressions and tests for aggregation bias. Journal of American Statistical Association, 57, 348-368.

Zhylyevskyy, O., Jensen, H.H., Garasky, S.B., Cutrona, C.E., \& Gibbons, F.X. (2013). Effects of family, friends, and relative prices on fruit and vegetable consumption by African Americans. Southern Economic Journal, 80, 226-251.

Zick, C.D., McCullough, J., \& Smith, K.R. (1996). Trade-offs between purchased services and time in single-parent and two-parent families. Journal of Consumer Affairs, 30, 1-23.

Zick, C.D., \& Stevens, R.B. (2010). Trends in Americans' food-related time use: 1975-2006. Public Health Nutrition, 13, 1064-1072. 


\section{Table 1. Construction of Analytical Sample}

\begin{tabular}{lcc}
\hline \multicolumn{1}{c}{ Data Processing Step } & Count & Fraction Retained, \% \\
\hline Initial sample of ATUS/EH Module records & 37,914 & - \\
Retain a record if the following condition is met: & & \\
Respondent completed EH Module interview & 37,832 & 99.78 \\
Household contains only one adult member & 11,870 & 31.38 \\
Respondent is of age 18 years or older & 11,564 & 30.57 \\
Household contains no children of age 16-17 years & 11,187 & 29.57 \\
Interview passes data quality check & 11,070 & 29.20 \\
\hline
\end{tabular}

Notes: The initial sample includes the ATUS/EH Module records, merged over the years 2006, 2007, and 2008. The table lists conditions that are applied in order to construct the analytical sample; it also shows how many records are retained after each data processing step. "Fraction Retained" refers to the number of retained records as a fraction of the initial sample.

${ }^{\text {a }}$ At this step, we retain records regardless of the presence and age of children in the household.

${ }^{\mathrm{b}}$ We drop data records marked as "low quality" in the ATUS Case History file.

Table 2. ATUS Lexicon Codes for Activities Related to Primary Eating and Food Preparation

\begin{tabular}{lr}
\hline \multicolumn{1}{c}{ Description } & ATUS Activity Codes \\
\hline Primary eating: & 110101 to 110199 \\
Eating and drinking & 119999 \\
Eating and drinking not elsewhere classified & 050202 \\
Eating and drinking as part of the job ${ }^{\mathrm{a}}$ & \\
Food preparation: & 020201 to 020299 \\
Food and drink preparation, presentation, and cleanup & 070101 \\
Grocery shopping & 180202 \\
Travel related to food and drink preparation, presentation, and cleanup & 180701 \\
Travel related to purchasing groceries & \\
\hline
\end{tabular}

Notes: This table lists codes for primary eating and food preparation activities from the ATUS lexicon.

${ }^{\text {a }}$ For example, a business dinner with clients. 
Table 3. Summary Statistics for Time in Eating and Food Preparation (Minutes per Day)

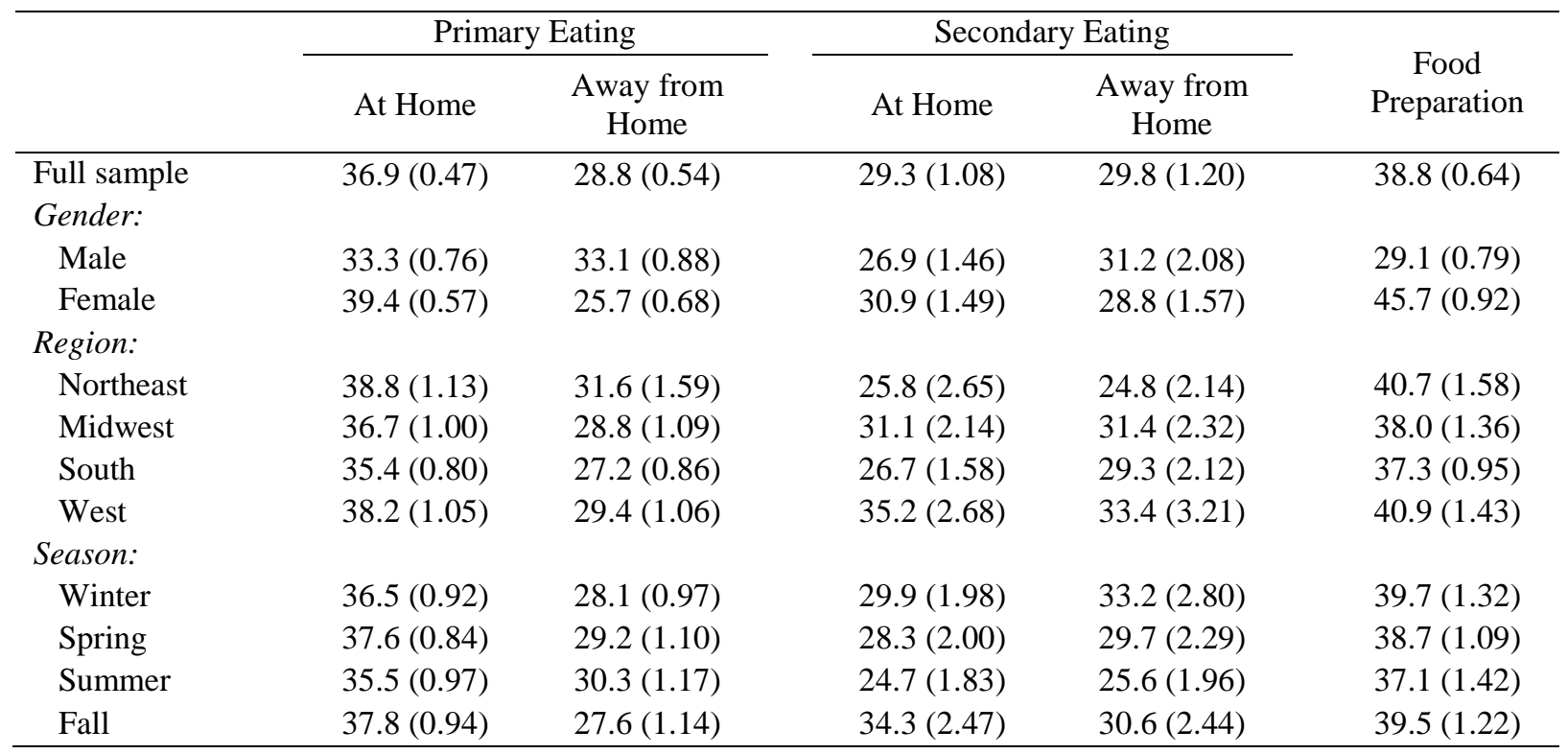

Notes: Means are calculated using the EH Module's sample weights. We calculate standard errors of the mean estimates (shown in parentheses) using the successive difference replication (SDR) method and the EH Module's replicate weights (BLS 2012, Ch. 7). The total number of respondents in the analytical sample is 11,070.

Table 4. Fraction of Cases with Zero Time in Eating and Food Preparation on Diary Day (\%)

\begin{tabular}{|c|c|c|c|c|c|}
\hline & \multicolumn{2}{|c|}{ No Primary Eating } & \multicolumn{2}{|c|}{ No Secondary Eating } & \multirow{2}{*}{$\begin{array}{l}\text { No Food } \\
\text { Preparation }\end{array}$} \\
\hline & At Home & $\begin{array}{c}\text { Away from } \\
\text { Home }\end{array}$ & At Home & $\begin{array}{c}\text { Away from } \\
\text { Home }\end{array}$ & \\
\hline Full sample & 22.4 & 52.0 & 64.7 & 69.3 & 38.1 \\
\hline \multicolumn{6}{|l|}{ Gender: } \\
\hline Male & 26.0 & 46.2 & 69.3 & 68.3 & 46.4 \\
\hline Female & 20.0 & 56.1 & 61.4 & 70.0 & 32.1 \\
\hline \multicolumn{6}{|l|}{ Region: } \\
\hline Northeast & 20.4 & 51.8 & 64.1 & 70.0 & 37.5 \\
\hline Midwest & 22.9 & 52.0 & 63.1 & 68.6 & 38.5 \\
\hline South & 23.3 & 52.3 & 66.8 & 70.2 & 38.8 \\
\hline West & 21.8 & 51.5 & 63.4 & 68.2 & 36.5 \\
\hline \multicolumn{6}{|l|}{ Season: } \\
\hline Winter & 22.2 & 50.7 & 64.1 & 67.4 & 36.4 \\
\hline Spring & 20.4 & 53.1 & 64.2 & 69.1 & 36.1 \\
\hline Summer & 25.3 & 50.4 & 66.9 & 70.8 & 41.0 \\
\hline Fall & 21.7 & 53.7 & 63.7 & 70.0 & 38.9 \\
\hline
\end{tabular}

Notes: Statistics are computed using the EH Module's sample weights. The total number of respondents in the analytical sample is 11,070 . 
Table 5. Summary Statistics for Prices, Respondent Characteristics, and Diary Day Attributes

\begin{tabular}{|c|c|c|c|c|c|}
\hline Variable & Mean & $\begin{array}{c}\text { Std. } \\
\text { Error }\end{array}$ & Variable & Mean & $\begin{array}{c}\text { Std. } \\
\text { Error }\end{array}$ \\
\hline Price variables (real \$): & & & Metropolitan status: & & \\
\hline Food-at-home price index & 0.24 & 0.0002 & Metropolitan area & 0.82 & 0.007 \\
\hline Fast food price index & 2.63 & 0.002 & Non-metropolitan area & 0.18 & 0.007 \\
\hline Food worker mean wage & 3.87 & 0.004 & Diary day falls on: & & \\
\hline \multicolumn{3}{|c|}{ Demographic and socioeconomic characteristics: } & Holiday & 0.02 & 0.002 \\
\hline Age (years) & 52.21 & 0.240 & Not a holiday & 0.98 & 0.002 \\
\hline Male & 0.42 & 0.006 & Day of the week: & & \\
\hline Female & 0.58 & 0.006 & Sunday & 0.14 & 0.003 \\
\hline White & 0.78 & 0.005 & Monday & 0.15 & 0.004 \\
\hline African American & 0.18 & 0.005 & Tuesday & 0.14 & 0.004 \\
\hline Other race & 0.04 & 0.002 & Wednesday & 0.14 & 0.005 \\
\hline Hispanic & 0.08 & 0.003 & Thursday & 0.14 & 0.005 \\
\hline Not Hispanic & 0.92 & 0.003 & Friday & 0.14 & 0.005 \\
\hline Foreign-born & 0.09 & 0.004 & Saturday & 0.15 & 0.003 \\
\hline U.S.-born & 0.91 & 0.004 & Region: & & \\
\hline Income is below $130 \%$ of & & & Northeast & 0.18 & 0.004 \\
\hline poverty line & 0.26 & 0.005 & Midwest & 0.27 & 0.005 \\
\hline Income is between $130 \%$ & & & South & 0.37 & 0.006 \\
\hline and $185 \%$ of poverty line & 0.13 & 0.004 & West & 0.18 & 0.005 \\
\hline Log of real family income & 8.53 & 0.047 & Year: & & \\
\hline Income is missing & 0.15 & 0.004 & 2006 & 0.32 & 0.005 \\
\hline Education: & & & 2007 & 0.33 & 0.006 \\
\hline Less than high school diploma & 0.14 & 0.004 & 2008 & 0.35 & 0.006 \\
\hline High school diploma & 0.31 & 0.005 & Season: & & \\
\hline Some college education & 0.27 & 0.005 & Winter & 0.25 & 0.005 \\
\hline Bachelor's or higher degree & 0.28 & 0.005 & Spring & 0.26 & 0.006 \\
\hline Presence of children: & & & Summer & 0.25 & 0.006 \\
\hline Age 0-5 years & 0.05 & 0.002 & Fall & 0.24 & 0.005 \\
\hline Age $6-15$ years & 0.10 & 0.003 & & & \\
\hline
\end{tabular}

Notes: Means are calculated using the EH Module's sample weights. We calculate standard errors of the mean estimates using the SDR method and the EH Module's replicate weights. The price variables, age, and log of real family income are continuous; all other variables are indicators. Nominal dollars are converted into real dollars using the CPI series (BLS 2013). The total number of respondents in the analytical sample is 11,070. 
Table 6. Tobit Models: Marginal Effects on Probability of Positive Activity Duration

\begin{tabular}{|c|c|c|c|c|c|c|c|c|c|c|}
\hline \multirow{3}{*}{$\begin{array}{c}\text { Variable } \\
\text { Food-at-home price index }\end{array}$} & \multicolumn{4}{|c|}{ Primary Eating } & \multicolumn{4}{|c|}{ Secondary Eating } & \multirow{2}{*}{\multicolumn{2}{|c|}{ Food Preparation }} \\
\hline & \multicolumn{2}{|c|}{ At Home } & \multicolumn{2}{|c|}{ Away from Home } & \multicolumn{2}{|c|}{ At Home } & \multicolumn{2}{|c|}{ Away from Home } & & \\
\hline & $0.58^{* * *}$ & $(0.23)$ & 0.32 & $(0.36)$ & -0.20 & $(0.21)$ & 0.28 & $(0.19)$ & $0.58^{* * *}$ & $(0.19)$ \\
\hline Fast food price index & $-0.03^{* *}$ & $(0.02)$ & -0.03 & $(0.03)$ & 0.03 & $(0.02)$ & 0.02 & $(0.02)$ & $0.06^{* *}$ & $(0.03)$ \\
\hline Age & $0.01^{* * *}$ & $(0.00)$ & $-0.004^{* * *}$ & $(0.00)$ & $0.001^{* * *}$ & $(0.00)$ & $-0.01^{* * *}$ & $(0.00)$ & $0.004^{* * *}$ & $(0.00)$ \\
\hline Male & -0.00 & $(0.01)$ & $0.03^{* * *}$ & $(0.01)$ & $-0.04^{* * *}$ & $(0.01)$ & $-0.02^{* * *}$ & $(0.01)$ & $-0.08^{* * *}$ & $(0.01)$ \\
\hline African American & $-0.07^{* * *}$ & $(0.01)$ & $-0.09^{* * *}$ & $(0.01)$ & $-0.02^{*}$ & $(0.01)$ & $-0.03^{* * *}$ & $(0.01)$ & -0.00 & $(0.01)$ \\
\hline Other race & $0.04^{* * *}$ & $(0.02)$ & -0.01 & $(0.02)$ & $-0.04^{*}$ & $(0.02)$ & $-0.04^{* *}$ & $(0.02)$ & 0.02 & $(0.03)$ \\
\hline Hispanic & $-0.04^{* * *}$ & $(0.01)$ & 0.02 & $(0.01)$ & $-0.07^{* * *}$ & $(0.01)$ & $-0.04^{* * *}$ & $(0.01)$ & 0.01 & $(0.01)$ \\
\hline Foreign-born & $0.04^{* * *}$ & $(0.01)$ & 0.01 & $(0.02)$ & $-0.05^{* * *}$ & $(0.01)$ & $-0.04^{* * *}$ & $(0.01)$ & $0.05^{* * *}$ & $(0.01)$ \\
\hline Income: < $130 \%$ poverty & $0.05^{* * *}$ & $(0.01)$ & $-0.13^{* * *}$ & $(0.01)$ & 0.01 & $(0.01)$ & $-0.05^{* * *}$ & $(0.01)$ & $0.04^{* * *}$ & $(0.01)$ \\
\hline Income: $130-185 \%$ poverty & $0.02^{* * *}$ & $(0.01)$ & $-0.03^{* *}$ & $(0.01)$ & 0.01 & $(0.01)$ & $-0.03^{* * *}$ & $(0.01)$ & $0.02^{*}$ & $(0.01)$ \\
\hline Log of real family income & $-0.02^{* * *}$ & $(0.01)$ & $0.03^{* * *}$ & $(0.01)$ & $-0.01^{* *}$ & $(0.01)$ & $0.03^{* * *}$ & $(0.01)$ & $-0.01^{* *}$ & $(0.00)$ \\
\hline Income is missing & $-0.22^{* * *}$ & $(0.05)$ & $0.32^{* * *}$ & $(0.05)$ & $-0.12^{* *}$ & $(0.05)$ & $0.30^{* * *}$ & $(0.07)$ & $-0.10^{* *}$ & $(0.05)$ \\
\hline High school diploma & 0.02 & $(0.01)$ & $0.04^{* * *}$ & $(0.01)$ & $0.03^{* *}$ & $(0.01)$ & $0.05^{* * *}$ & $(0.01)$ & -0.01 & $(0.01)$ \\
\hline Some college education & 0.02 & $(0.01)$ & $0.06^{* * *}$ & $(0.02)$ & $0.05^{* * *}$ & $(0.01)$ & $0.07^{* * *}$ & $(0.02)$ & -0.00 & $(0.01)$ \\
\hline Bachelor’s/higher degree & $0.04^{* * *}$ & $(0.01)$ & $0.08^{* * *}$ & $(0.02)$ & $0.06^{* * *}$ & $(0.02)$ & $0.10^{* * *}$ & $(0.02)$ & -0.00 & $(0.01)$ \\
\hline Presence of child, age $0-5$ & $0.02^{* *}$ & $(0.01)$ & $-0.03^{*}$ & $(0.02)$ & -0.00 & $(0.02)$ & -0.02 & $(0.02)$ & $0.11^{* * *}$ & $(0.02)$ \\
\hline Presence of child, age 6-15 & $0.04^{* * *}$ & $(0.01)$ & $-0.05^{* * *}$ & $(0.01)$ & $0.04^{* * *}$ & $(0.01)$ & 0.01 & $(0.01)$ & $0.13^{* * *}$ & $(0.01)$ \\
\hline Metropolitan area & -0.00 & $(0.01)$ & 0.02 & $(0.01)$ & $0.02^{*}$ & $(0.01)$ & 0.00 & $(0.01)$ & -0.01 & $(0.01)$ \\
\hline Holiday & -0.01 & $(0.03)$ & 0.05 & $(0.04)$ & 0.02 & $(0.03)$ & -0.02 & $(0.03)$ & $0.08^{* *}$ & $(0.03)$ \\
\hline Sunday & 0.01 & $(0.01)$ & $-0.03^{*}$ & $(0.01)$ & $0.06^{* * *}$ & $(0.02)$ & $-0.07^{* * *}$ & $(0.02)$ & 0.02 & $(0.01)$ \\
\hline Monday & -0.00 & $(0.01)$ & -0.02 & $(0.01)$ & $0.03^{*}$ & $(0.02)$ & $0.03^{*}$ & $(0.02)$ & -0.00 & $(0.01)$ \\
\hline Tuesday & -0.00 & $(0.01)$ & -0.01 & $(0.01)$ & 0.02 & $(0.02)$ & 0.01 & $(0.01)$ & 0.01 & $(0.02)$ \\
\hline Thursday & 0.00 & $(0.01)$ & 0.00 & $(0.02)$ & 0.01 & $(0.02)$ & 0.01 & $(0.02)$ & 0.01 & $(0.01)$ \\
\hline Friday & $-0.02^{*}$ & $(0.01)$ & $0.03^{* *}$ & $(0.01)$ & 0.02 & $(0.02)$ & 0.01 & $(0.01)$ & $-0.03^{* *}$ & $(0.01)$ \\
\hline Saturday & -0.01 & $(0.01)$ & 0.00 & $(0.01)$ & $0.04^{* * *}$ & $(0.02)$ & -0.00 & $(0.01)$ & $0.03^{* *}$ & $(0.01)$ \\
\hline Region, year, season dummies & \multicolumn{2}{|c|}{ Included } & \multicolumn{2}{|c|}{ Included } & \multicolumn{2}{|c|}{ Included } & \multicolumn{2}{|c|}{ Included } & \multicolumn{2}{|c|}{ Included } \\
\hline LM specification test & \multicolumn{2}{|c|}{$338.63^{* * *}(7.01)$} & \multicolumn{2}{|c|}{$4.83^{* *}(6.06)$} & \multicolumn{2}{|c|}{$1614.70^{* * *}(7.85)$} & \multicolumn{2}{|c|}{$1107.10^{* * *}(8.39)$} & \multicolumn{2}{|c|}{$338.72^{* * *}(7.62)$} \\
\hline
\end{tabular}

Notes: Standard errors (reported in parentheses) are clustered at the state level. The last row reports the test statistic value and bootstrapped 1\% critical value (in parenthesis) from a Lagrange multiplier (LM) test of the null hypothesis of normality and homoscedasticity of the Tobit model's error terms and linearity of the model's latent variable in the explanatory variables. Statistical significance: ${ }^{*} p<0.10,{ }^{* *} p<0.05,{ }^{* * *} p<0.01$. 
Table 7. Double-Hurdle Models: Marginal Effects on Probability of Positive Activity Duration

\begin{tabular}{|c|c|c|c|c|c|c|c|c|c|c|}
\hline \multirow{3}{*}{$\begin{array}{c}\text { Variable } \\
\text { Food-at-home price index }\end{array}$} & \multicolumn{4}{|c|}{ Primary Eating } & \multicolumn{4}{|c|}{ Secondary Eating } & \multirow{2}{*}{\multicolumn{2}{|c|}{ Food Preparation }} \\
\hline & \multicolumn{2}{|c|}{ At Home } & \multicolumn{2}{|c|}{ Away from Home } & \multicolumn{2}{|c|}{ At Home } & \multicolumn{2}{|c|}{ Away from Home } & & \\
\hline & $0.57^{* * *}$ & $(0.22)$ & -0.17 & $(0.35)$ & -0.11 & $(0.25)$ & 0.32 & $(0.24)$ & 0.39 & $(0.28)$ \\
\hline Fast food price index & -0.03 & $(0.02)$ & -0.04 & $(0.03)$ & $0.06^{* * *}$ & $(0.02)$ & 0.02 & $(0.02)$ & $0.07^{*}$ & $(0.04)$ \\
\hline Age & $0.01^{* * *}$ & $(0.00)$ & $-0.01^{* * *}$ & $(0.00)$ & $0.001^{* * *}$ & $(0.00)$ & $-0.01^{* * *}$ & $(0.00)$ & $0.005^{* * *}$ & $(0.00)$ \\
\hline Male & $-0.02^{* *}$ & $(0.01)$ & $0.02^{* *}$ & $(0.01)$ & $-0.07^{* * *}$ & $(0.01)$ & $-0.04^{* * *}$ & $(0.01)$ & $-0.08^{* * *}$ & $(0.01)$ \\
\hline African American & $-0.04^{* * *}$ & $(0.01)$ & $-0.07^{* * *}$ & $(0.01)$ & $-0.03^{* *}$ & $(0.01)$ & $-0.03^{*}$ & $(0.01)$ & $-0.04^{* * *}$ & $(0.01)$ \\
\hline Other race & 0.01 & $(0.03)$ & -0.01 & $(0.02)$ & $-0.05^{* *}$ & $(0.03)$ & $-0.04^{*}$ & $(0.02)$ & $-0.04^{*}$ & $(0.03)$ \\
\hline Hispanic & $-0.03^{*}$ & $(0.02)$ & $0.05^{* * *}$ & $(0.02)$ & $-0.07^{* * *}$ & $(0.01)$ & $-0.04^{* * *}$ & $(0.01)$ & -0.01 & $(0.01)$ \\
\hline Foreign-born & $0.05^{* * *}$ & $(0.02)$ & 0.02 & $(0.02)$ & $-0.07^{* * *}$ & $(0.01)$ & $-0.04^{* *}$ & $(0.02)$ & $0.03^{*}$ & $(0.02)$ \\
\hline Income: < $130 \%$ poverty & $0.06^{* * *}$ & $(0.01)$ & $-0.14^{* * *}$ & $(0.01)$ & 0.00 & $(0.01)$ & $-0.05^{* * *}$ & $(0.01)$ & $0.04^{* * *}$ & $(0.01)$ \\
\hline Income: $130-185 \%$ poverty & 0.01 & $(0.01)$ & $-0.04^{* * *}$ & $(0.01)$ & -0.00 & $(0.01)$ & $-0.03^{* * *}$ & $(0.01)$ & 0.01 & $(0.01)$ \\
\hline Log of real family income & $-0.02^{* * *}$ & $(0.00)$ & $0.04^{* * *}$ & $(0.01)$ & -0.00 & $(0.01)$ & $0.03^{* * *}$ & $(0.01)$ & $-0.01^{* * *}$ & $(0.00)$ \\
\hline Income is missing & $-0.22^{* * *}$ & $(0.05)$ & $0.41^{* * *}$ & $(0.07)$ & -0.06 & $(0.06)$ & $0.32^{* * *}$ & $(0.07)$ & $-0.15^{* * *}$ & $(0.05)$ \\
\hline High school diploma & -0.02 & $(0.02)$ & $0.05^{* * *}$ & $(0.02)$ & $0.03^{* *}$ & $(0.01)$ & $0.05^{* * *}$ & $(0.01)$ & 0.00 & $(0.01)$ \\
\hline Some college education & -0.02 & $(0.02)$ & $0.06^{* * *}$ & $(0.02)$ & $0.05^{* * *}$ & $(0.01)$ & $0.07^{* * *}$ & $(0.01)$ & 0.01 & $(0.02)$ \\
\hline Bachelor's/higher degree & -0.00 & $(0.02)$ & $0.07^{* * *}$ & $(0.02)$ & $0.08^{* * *}$ & $(0.01)$ & $0.12^{* * *}$ & $(0.02)$ & 0.02 & $(0.02)$ \\
\hline Presence of child, age $0-5$ & 0.02 & $(0.02)$ & $-0.04^{*}$ & $(0.02)$ & 0.01 & $(0.03)$ & -0.01 & $(0.02)$ & $0.14^{* * *}$ & $(0.02)$ \\
\hline Presence of child, age 6-15 & $0.04^{* * *}$ & $(0.01)$ & $-0.04^{* * *}$ & $(0.01)$ & $0.04^{* * *}$ & $(0.01)$ & 0.00 & $(0.02)$ & $0.14^{* * *}$ & $(0.02)$ \\
\hline Metropolitan area & -0.01 & $(0.01)$ & 0.01 & $(0.01)$ & $0.02^{*}$ & $(0.01)$ & -0.00 & $(0.01)$ & -0.01 & $(0.01)$ \\
\hline Holiday & $-0.06^{* *}$ & $(0.03)$ & 0.02 & $(0.04)$ & 0.03 & $(0.04)$ & -0.04 & $(0.04)$ & 0.00 & $(0.03)$ \\
\hline Sunday & -0.02 & $(0.01)$ & $-0.08^{* * *}$ & $(0.02)$ & $0.06^{* * *}$ & $(0.02)$ & $-0.10^{* * *}$ & $(0.02)$ & $-0.04^{*}$ & $(0.02)$ \\
\hline Monday & 0.01 & $(0.02)$ & 0.00 & $(0.02)$ & 0.03 & $(0.02)$ & 0.02 & $(0.02)$ & 0.00 & $(0.02)$ \\
\hline Tuesday & -0.02 & $(0.01)$ & -0.00 & $(0.02)$ & 0.01 & $(0.02)$ & 0.00 & $(0.02)$ & -0.01 & $(0.02)$ \\
\hline Thursday & -0.02 & $(0.02)$ & 0.01 & $(0.02)$ & -0.00 & $(0.02)$ & 0.01 & $(0.02)$ & 0.00 & $(0.02)$ \\
\hline Friday & $-0.03^{*}$ & $(0.02)$ & 0.03 & $(0.02)$ & 0.02 & $(0.02)$ & 0.00 & $(0.02)$ & $-0.04^{*}$ & $(0.02)$ \\
\hline Saturday & $-0.02^{* *}$ & $(0.01)$ & $-0.05^{* * *}$ & $(0.02)$ & $0.04^{* *}$ & $(0.02)$ & $-0.03^{*}$ & $(0.02)$ & -0.02 & $(0.02)$ \\
\hline Region, year, season dummies & \multicolumn{2}{|c|}{ Included } & \multicolumn{2}{|c|}{ Included } & \multicolumn{2}{|c|}{ Included } & \multicolumn{2}{|c|}{ Included } & \multicolumn{2}{|c|}{ Included } \\
\hline LR specification test & \multicolumn{2}{|c|}{$417.08^{* * *}(0.00)$} & \multicolumn{2}{|c|}{$403.86^{* * *}(0.00)$} & \multicolumn{2}{|c|}{$1,377.85^{* * *}(0.00)$} & \multicolumn{2}{|c|}{$714.17^{* * *}(0.00)$} & \multicolumn{2}{|c|}{$541.35^{* * *}(0.00)$} \\
\hline
\end{tabular}

Notes: Standard errors (reported in parentheses) are clustered at the state level. The last row reports the test statistic value and $p$-value (in parenthesis) from a likelihood ratio (LR) test of the null hypothesis of the applicability of the Tobit model to describe the data. A rejection of the null hypothesis here implies a rejection of the Tobit model in favor of the double-hurdle model. Statistical significance: ${ }^{*} p<0.10,{ }^{* *} p<0.05$, ${ }^{* * *} p<0.01$. 
Table 8. Tobit Models: Marginal Effects on Expected Activity Duration (Minutes per Day)

\begin{tabular}{|c|c|c|c|c|c|c|c|c|c|c|}
\hline \multirow{3}{*}{$\begin{array}{c}\text { Variable } \\
\text { Food-at-home price index }\end{array}$} & \multicolumn{4}{|c|}{ Primary Eating } & \multicolumn{4}{|c|}{ Secondary Eating } & \multirow{2}{*}{\multicolumn{2}{|c|}{ Food Preparation }} \\
\hline & \multicolumn{2}{|c|}{ At Home } & \multicolumn{2}{|c|}{ Away from Home } & \multicolumn{2}{|c|}{ At Home } & \multicolumn{2}{|c|}{ Away from Home } & & \\
\hline & $65.18^{* * *}$ & $(25.36)$ & 30.41 & $(33.41)$ & -34.40 & (36.94) & 49.23 & $(33.50)$ & $75.59^{* * *}$ & $(24.00)$ \\
\hline Fast food price index & $-3.72^{* *}$ & $(1.88)$ & -3.01 & $(2.54)$ & 5.99 & $(4.20)$ & 3.32 & (3.35) & $7.14^{* *}$ & $(3.61)$ \\
\hline Age & $0.64^{* * *}$ & $(0.02)$ & $-0.36^{* * *}$ & $(0.04)$ & $0.14^{* * *}$ & $(0.04)$ & $-0.89^{* * *}$ & $(0.06)$ & $0.55^{* * *}$ & $(0.04)$ \\
\hline Male & -0.28 & $(0.74)$ & $2.42^{* * *}$ & $(0.92)$ & $-6.95^{* * *}$ & $(1.51)$ & $-4.05^{* * *}$ & $(1.29)$ & $-10.39^{* * *}$ & $(1.07)$ \\
\hline African American & $-6.84^{* * *}$ & $(0.81)$ & $-7.70^{* * *}$ & (1.01) & $-3.85^{*}$ & $(2.10)$ & $-5.45^{* * *}$ & (1.97) & -0.27 & (1.39) \\
\hline Other race & $5.13^{* * *}$ & (1.99) & -1.25 & $(2.00)$ & $-6.11^{*}$ & (3.53) & $-6.36^{* *}$ & (2.92) & 2.28 & $(3.40)$ \\
\hline Hispanic & $-3.91^{* * *}$ & (1.02) & 1.86 & (1.35) & $-11.85^{* * *}$ & (1.71) & $-7.47^{* * *}$ & (1.61) & 1.28 & $(1.24)$ \\
\hline Foreign-born & $4.33^{* * *}$ & $(1.21)$ & 0.69 & (1.99) & $-8.76^{* * *}$ & $(2.00)$ & $-6.29^{* * *}$ & $(2.31)$ & $6.30^{* * *}$ & $(2.08)$ \\
\hline Income: < $130 \%$ poverty & $5.49^{* * *}$ & $(0.88)$ & $-11.24^{* * *}$ & $(0.85)$ & 2.57 & (1.65) & $-8.01^{* * *}$ & (2.05) & $5.55^{* * *}$ & $(1.25)$ \\
\hline Income: $130-185 \%$ poverty & $2.73^{* * *}$ & $(0.96)$ & $-2.77^{* *}$ & (1.14) & 1.69 & $(2.58)$ & $-4.63^{* * *}$ & $(1.74)$ & $3.18^{*}$ & $(1.72)$ \\
\hline Log of real family income & $-2.34^{* * *}$ & $(0.57)$ & $3.25^{* * *}$ & $(0.65)$ & $-1.91^{* *}$ & $(0.91)$ & $4.82^{* * *}$ & (1.12) & $-1.24^{* *}$ & $(0.58)$ \\
\hline Income is missing & $-20.11^{* * *}$ & $(4.09)$ & $41.35^{* * *}$ & (10.63) & $-19.11^{* * *}$ & (7.29) & $69.67^{* * *}$ & $(22.82)$ & $-12.11^{* *}$ & $(5.10)$ \\
\hline High school diploma & 1.83 & (1.53) & $4.05^{* * *}$ & $(1.44)$ & $5.41^{* *}$ & $(2.48)$ & $9.25^{* * *}$ & $(2.67)$ & -0.99 & $(1.35)$ \\
\hline Some college education & 2.30 & (1.65) & $5.82^{* * *}$ & (1.56) & $8.31^{* * *}$ & (2.57) & $12.96^{* * *}$ & (3.05) & -0.52 & $(1.54)$ \\
\hline Bachelor's/higher degree & $4.27^{* * *}$ & $(1.60)$ & $7.59^{* * *}$ & (1.51) & $11.44^{* * *}$ & (2.83) & $18.07^{* * *}$ & $(3.45)$ & -0.63 & $(1.74)$ \\
\hline Presence of child, age $0-5$ & $2.89^{* *}$ & (1.46) & $-2.64^{*}$ & $(1.50)$ & -0.17 & (3.32) & -3.44 & (2.69) & $16.58^{* * *}$ & $(2.52)$ \\
\hline Presence of child, age 6-15 & $4.46^{* * *}$ & $(0.95)$ & $-4.63^{* * *}$ & (1.06) & $6.19^{* * *}$ & (1.95) & 1.01 & (2.43) & $19.27^{* * *}$ & $(1.54)$ \\
\hline Metropolitan area & -0.55 & $(0.90)$ & 1.43 & $(1.20)$ & $3.49^{*}$ & (1.84) & 0.34 & $(2.05)$ & -1.69 & (1.18) \\
\hline Holiday & -1.45 & (3.43) & 5.14 & (3.84) & 2.94 & (5.69) & -4.10 & (5.09) & $10.99^{* *}$ & $(5.01)$ \\
\hline Sunday & 0.99 & (1.17) & $-2.49^{*}$ & (1.32) & $10.91^{* * *}$ & $(2.71)$ & $-12.22^{* * *}$ & $(2.45)$ & 2.50 & $(1.56)$ \\
\hline Monday & -0.30 & $(1.20)$ & -1.53 & (1.11) & $4.96^{*}$ & $(2.95)$ & $4.64^{*}$ & $(2.74)$ & -0.28 & $(1.89)$ \\
\hline Tuesday & -0.19 & (1.57) & -0.63 & (1.31) & 3.89 & (3.15) & 1.21 & $(2.44)$ & 0.68 & (2.13) \\
\hline Thursday & 0.01 & (1.61) & 0.44 & (1.66) & 1.05 & (2.91) & 2.40 & $(2.71)$ & 0.68 & $(1.86)$ \\
\hline Friday & $-2.42^{*}$ & $(1.40)$ & $3.12^{* *}$ & (1.38) & 3.55 & (3.47) & 2.02 & (2.42) & $-3.42^{* *}$ & $(1.69)$ \\
\hline Saturday & -0.79 & $(1.12)$ & 0.22 & (1.16) & $7.65^{* *}$ & (3.02) & -0.66 & (2.19) & $3.74^{* *}$ & $(1.52)$ \\
\hline Region, year, season dummies & \multicolumn{2}{|c|}{ Included } & \multicolumn{2}{|c|}{ Included } & \multicolumn{2}{|c|}{ Included } & \multicolumn{2}{|c|}{ Included } & \multicolumn{2}{|c|}{ Included } \\
\hline
\end{tabular}

Notes: Standard errors (reported in parentheses) are clustered at the state level. The reported marginal effects account for the fact that the time in an activity cannot be negative. Statistical significance: ${ }^{*} p<0.10,{ }^{* *} p<0.05,{ }^{* * *} p<0.01$. 
Table 9. Double-Hurdle Models: Marginal Effects on Expected Activity Duration (Minutes per Day)

\begin{tabular}{|c|c|c|c|c|c|c|c|c|c|c|}
\hline \multirow{3}{*}{$\begin{array}{c}\text { Variable } \\
\text { Food-at-home price index }\end{array}$} & \multicolumn{4}{|c|}{ Primary Eating } & \multicolumn{4}{|c|}{ Secondary Eating } & \multirow{2}{*}{\multicolumn{2}{|c|}{ Food Preparation }} \\
\hline & \multicolumn{2}{|c|}{ At Home } & \multicolumn{2}{|c|}{ Away from Home } & \multicolumn{2}{|c|}{ At Home } & \multicolumn{2}{|c|}{ Away from Home } & & \\
\hline & $66.90^{* *}$ & $(29.28)$ & 55.61 & $(37.10)$ & -75.51 & $(59.74)$ & 38.56 & $(48.22)$ & $85.62^{* * *}$ & $(27.25)$ \\
\hline Fast food price index & $-3.83^{*}$ & $(2.06)$ & -2.54 & $(2.73)$ & 1.33 & $(5.16)$ & 4.07 & (4.99) & $6.68^{*}$ & (3.84) \\
\hline Age & $0.66^{* * *}$ & $(0.03)$ & $-0.28^{* * *}$ & $(0.04)$ & $0.14^{* *}$ & $(0.07)$ & $-0.75^{* * *}$ & $(0.07)$ & $0.53^{* * *}$ & $(0.04)$ \\
\hline Male & 0.29 & $(0.80)$ & $2.70^{* * *}$ & $(0.96)$ & -1.16 & (1.89) & -1.80 & (1.66) & $-10.58^{* * *}$ & $(1.24)$ \\
\hline African American & $-8.45^{* * *}$ & $(1.16)$ & $-10.20^{* * *}$ & $(1.23)$ & -2.80 & $(2.73)$ & $-7.70^{* *}$ & $(3.26)$ & 1.71 & $(1.53)$ \\
\hline Other race & $5.87^{* * *}$ & (1.73) & -0.71 & $(2.18)$ & -3.57 & (5.36) & -6.90 & (4.69) & $5.36^{*}$ & $(3.10)$ \\
\hline Hispanic & $-4.13^{* * *}$ & $(0.88)$ & -0.10 & $(1.60)$ & $-17.22^{* * *}$ & $(5.88)$ & $-13.17^{* * *}$ & (4.43) & 2.36 & (1.61) \\
\hline Foreign-born & $4.02^{* * *}$ & $(1.21)$ & -0.23 & (2.29) & $-7.80^{* *}$ & (3.75) & $-9.30^{* *}$ & (3.75) & $6.66^{* * *}$ & $(2.06)$ \\
\hline Income: < $130 \%$ poverty & $5.54^{* * *}$ & $(0.91)$ & $-10.96^{* * *}$ & (1.34) & $4.75^{* *}$ & $(2.36)$ & $-8.26^{* *}$ & $(3.70)$ & $5.30^{* * *}$ & $(1.35)$ \\
\hline Income: $130-185 \%$ poverty & $2.95^{* * *}$ & $(1.00)$ & -1.85 & (1.35) & 3.95 & (3.14) & -3.51 & (2.66) & $3.72^{* *}$ & $(1.86)$ \\
\hline Log of real family income & $-2.36^{* * *}$ & $(0.63)$ & $2.87^{* * *}$ & $(0.76)$ & $-2.83^{* *}$ & (1.23) & $3.91^{* *}$ & (1.66) & -1.09 & $(0.68)$ \\
\hline Income is missing & $-22.71^{* * *}$ & $(6.03)$ & $27.56^{* * *}$ & (7.90) & $-30.26^{* *}$ & (12.57) & $38.99^{* *}$ & $(16.85)$ & -11.07 & (6.97) \\
\hline High school diploma & 2.08 & (1.64) & $2.82^{*}$ & (1.52) & 5.32 & (3.41) & $11.47^{* *}$ & (4.89) & -1.15 & $(1.58)$ \\
\hline Some college education & 2.80 & $(1.76)$ & $4.90^{* * *}$ & (1.53) & $6.91^{*}$ & $(3.88)$ & $15.12^{* * *}$ & $(5.64)$ & -1.07 & $(1.61)$ \\
\hline Bachelor's/higher degree & $4.65^{* * *}$ & $(1.80)$ & $6.99^{* * *}$ & (1.58) & $7.72^{* *}$ & (3.80) & $15.74^{* * *}$ & $(5.76)$ & -1.64 & (1.97) \\
\hline Presence of child, age $0-5$ & 2.43 & $(1.48)$ & $-3.46^{* *}$ & $(1.71)$ & -1.49 & (3.82) & -5.22 & $(4.00)$ & $14.40^{* * *}$ & (2.29) \\
\hline Presence of child, age $6-15$ & $4.01^{* * *}$ & (1.11) & $-6.15^{* * *}$ & (1.36) & $5.01^{*}$ & $(2.86)$ & 1.22 & (2.77) & $17.23^{* * *}$ & (1.35) \\
\hline Metropolitan area & -0.43 & $(0.98)$ & 2.21 & (1.37) & 3.60 & $(2.48)$ & 1.09 & (2.65) & -1.94 & $(1.31)$ \\
\hline Holiday & 0.28 & $(3.62)$ & $6.45^{*}$ & (3.41) & 2.44 & $(7.59)$ & -1.04 & $(5.67)$ & $12.77^{* * *}$ & $(4.42)$ \\
\hline Sunday & 1.58 & (1.35) & 0.51 & $(1.29)$ & $11.27^{* * *}$ & (3.51) & $-10.88^{* * *}$ & (4.14) & $5.64^{* * *}$ & $(1.92)$ \\
\hline Monday & -0.64 & $(1.27)$ & $-3.23^{* *}$ & $(1.37)$ & 5.22 & $(4.21)$ & 5.17 & (3.34) & -0.82 & (2.39) \\
\hline Tuesday & 0.20 & $(1.84)$ & -0.78 & (1.55) & $6.48^{*}$ & (3.73) & 1.42 & (3.56) & 1.63 & $(2.48)$ \\
\hline Thursday & 0.41 & $(1.68)$ & 0.41 & $(1.71)$ & 3.77 & $(4.00)$ & 4.42 & (3.87) & 0.67 & $(2.56)$ \\
\hline Friday & -2.37 & (1.59) & $3.86^{* * *}$ & $(1.45)$ & 5.07 & $(4.46)$ & 3.74 & $(2.70)$ & $-3.22^{*}$ & (1.93) \\
\hline Saturday & -0.45 & $(1.22)$ & $3.37^{* * *}$ & $(1.25)$ & $8.58^{* *}$ & $(4.02)$ & 3.83 & $(3.27)$ & $6.42^{* * *}$ & $(1.82)$ \\
\hline Region, year, season dummies & \multicolumn{2}{|c|}{ Included } & \multicolumn{2}{|c|}{ Included } & \multicolumn{2}{|c|}{ Included } & \multicolumn{2}{|c|}{ Included } & \multicolumn{2}{|c|}{ Included } \\
\hline
\end{tabular}

Notes: Standard errors (reported in parentheses) are clustered at the state level. The reported marginal effects account for the fact that the time in an activity cannot be negative. Statistical significance: ${ }^{*} p<0.10,{ }^{* *} p<0.05,{ }^{* * *} p<0.01$. 